This article has been scanned by iThenticat No plagiarism detected

Volume 3, Issue 6, December 2021

p. 281-295

\title{
FINANCING PUBLIC UNIVERSITIES IN PALESTINE: CHALLENGES AND OPPORTUNITIES
}

http://dx.doi.org/10.47832/2757-5403.6-3.20

\author{
Moammar Abdelrahman SHABIB ${ }^{1}$, Amal MASHAL 2 \& Thaer Ali RAJA 3
}

\begin{abstract}
:
The purpose of the study to identify the extent to which the sustainability of sources of financing and to identify the most important challenges facing the financing of the Palestinian public universities as well as to explore potential financing opportunities that can be developed to finance the Palestinian public universities based on the experiences of other universities. The study used the analytical qualitative method, and the study tool is interviews with finance specialists in Palestinian public universities. One of the findings of the study is that students' tuition fees are the main source of financing for universities, as they constitute approximately $80 \%$ of universities' revenues. The centers and institutes affiliated with the university are considered an important and sustainable source of financing for universities, but they are not used in an optimal way. One of the challenges facing financing is competition between universities instead of integration between them, and from other financing opportunities, are creation of investment units in universities or business development centers in partnership with the private sector .The study recommended the importance of working on finding other sources of financing universities through potential financing opportunities, such as : investment units and business development centers, establishing productive projects in cooperation and partnership with the public and private sectors, restructuring and integrating academic disciplines, and finding new academic disciplines that match with the labor market requirements that attract new students.
\end{abstract}

\footnotetext{
${ }^{1}$ Researcher , Arab American University, Palestine, moammarshabib@yahoo.com, https://orcid.org/00000002-4969-7668

${ }^{2}$ Researcher , Arab American University, Palestine, amalmashal78@gmail.com, https://orcid.org/0000-0002$\underline{5396-2671}$

${ }^{3}$ Researcher , Arab American University, Palestine, Thaer.atheer.28@hotmail.com, https://orcid.org/0000$\underline{0002-8509-5701}$
}

Copyright (C) Published by IJHER Journal, www.ijherjournal.com Rimar Academy, Fatih, Istanbul, 34093 Turkey

All rights reserved 
Key words: Financing, University Education Financing, Public University Financing, Higher Education Financing.

تمويل التعليم الجامعي العام في فلسطين: الفرص والتحديات

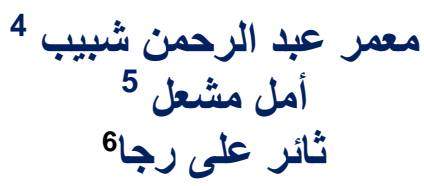

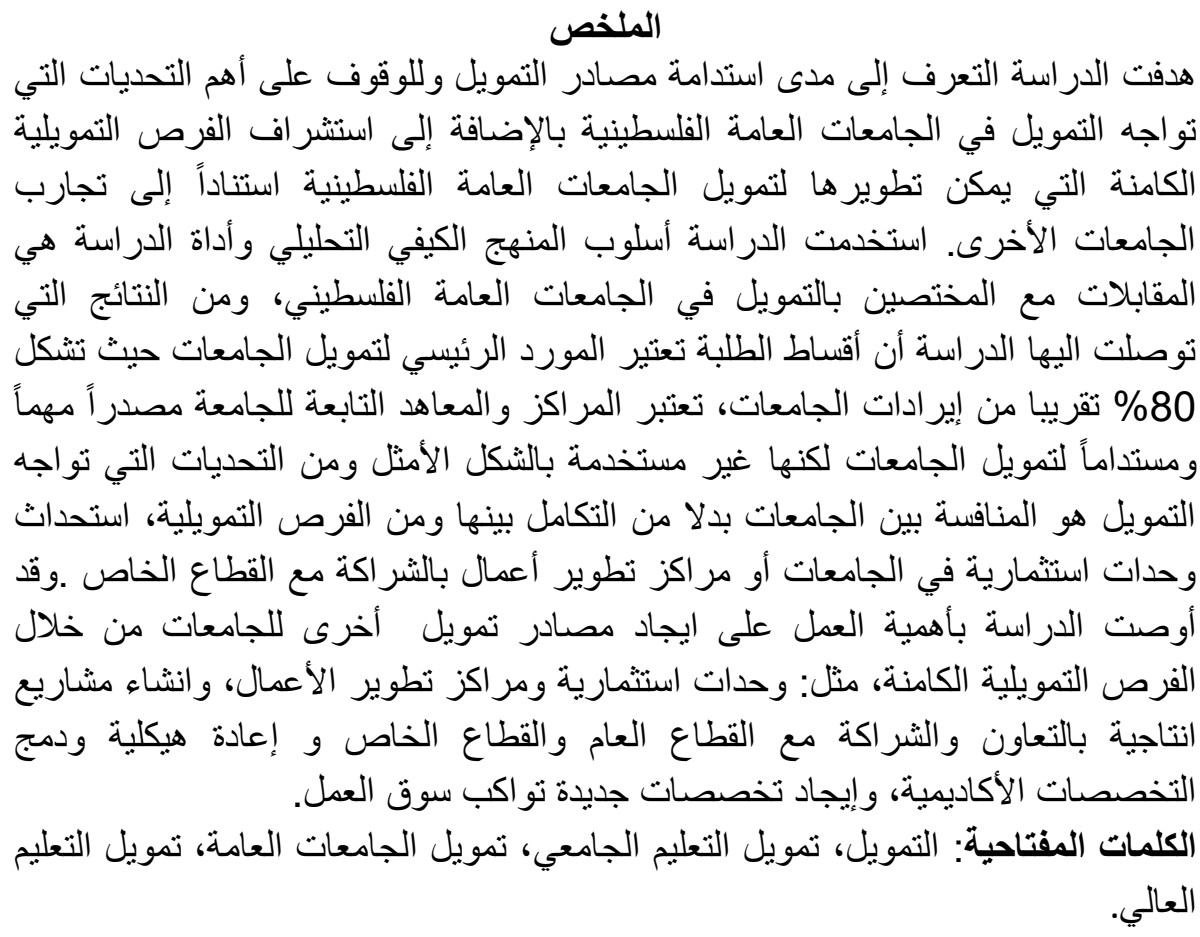

إن إيجاد مصادر تمويل للتعليم العالي بات من أكثر الاهتمامات التي تشغل بال صنُّاع القرار و المهتمين في التعليم الجامعي بشكل خاص. خاصة بعد جائحة كورونا ووجود تحديات كثيرة على ضوء المتغير التير ات الاجتماعية و الاقتصادية في في جميع انحاء العالم وبما فيها فلسطين. و لأن التعليم حق أساسي للإنسان (المورد البشري) في كل مراحل حياته، لا بد من الاستثمار فيه و العمل على تمويل

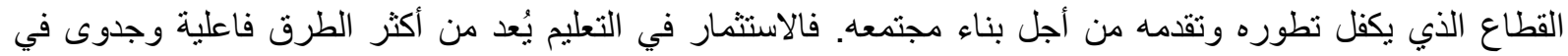

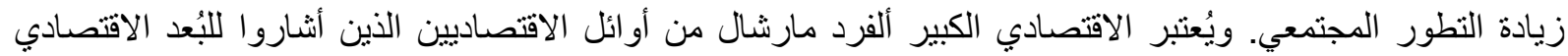

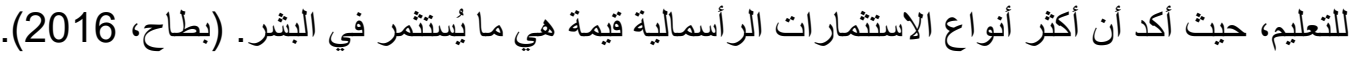

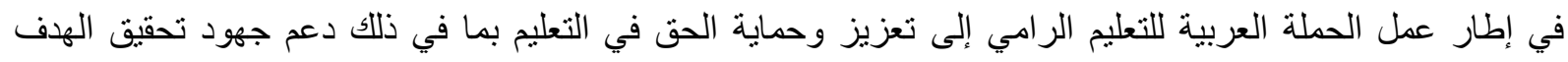

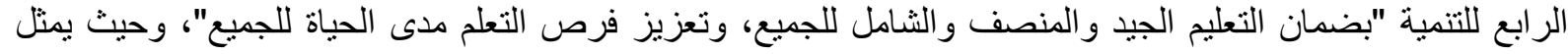

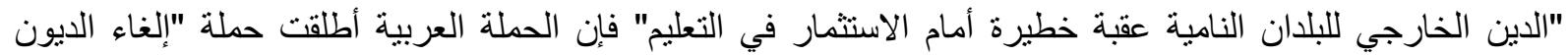

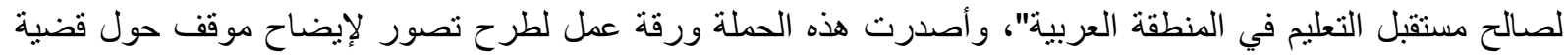

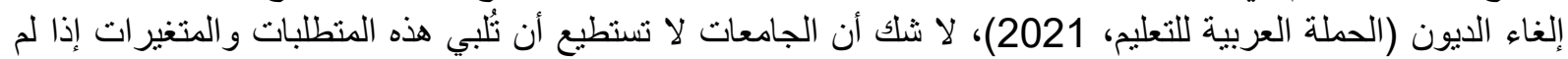


يتوفر لديها التمويل اللازم. وعلى الرغم من الظروف الاقتصادية التي تمر الدول العربية إلا أنه من المهم زيادة تمويل

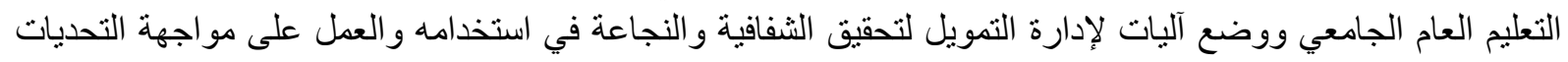

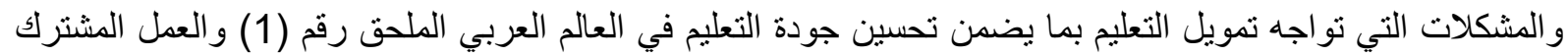
بين الدول العربية في مجال التعليم العالي وتعزيز البحث العلمي بما يساهم في تحقيق تنمية مستدامة وحقيقية في جميع

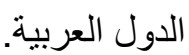

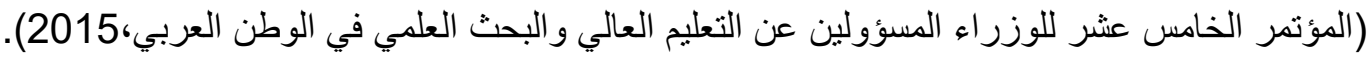

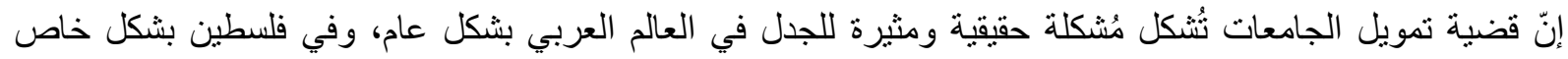

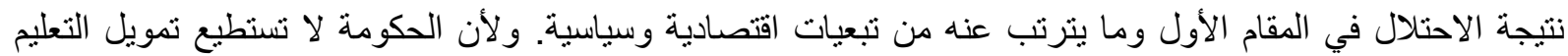

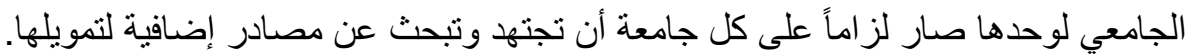

وتعتمد الجامعات في الدول العربية على عدة مصادر لتمويل التعليم العام في الجامعات، وهي: 1-أقساط الطلاب الدراسية.2-الهبات والمنح والمساعدات الخارجية.3-القروض الخارجية مثل قروض الإنس الحكومات

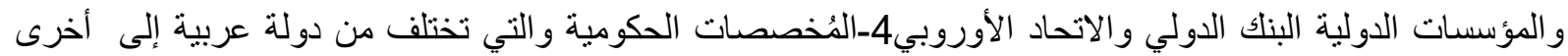

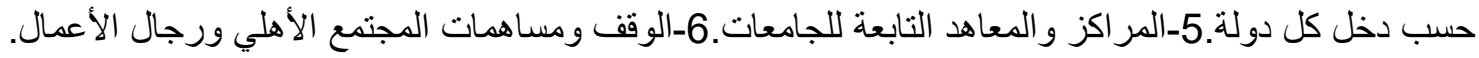

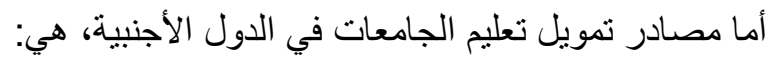

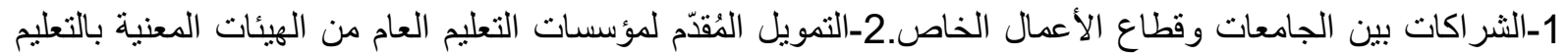

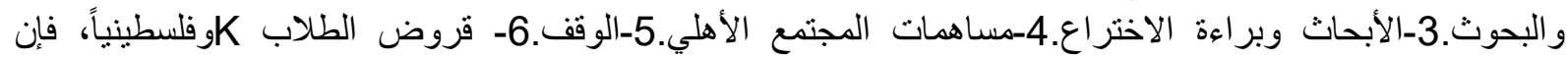

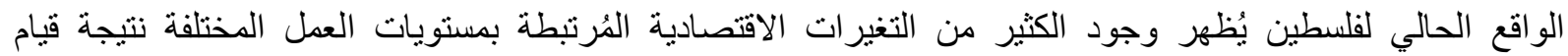

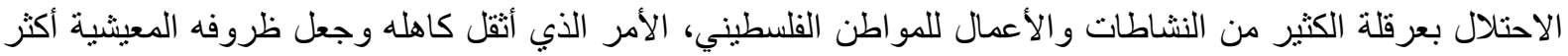

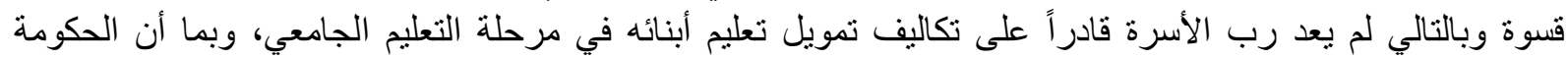

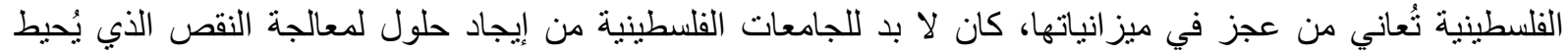

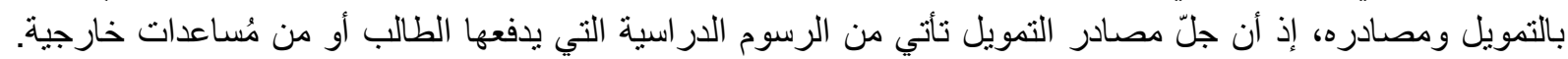

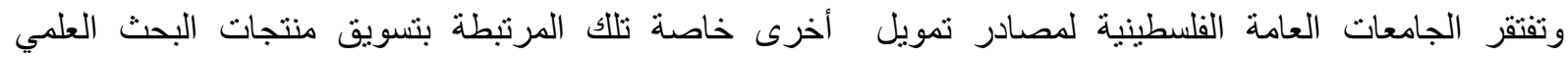

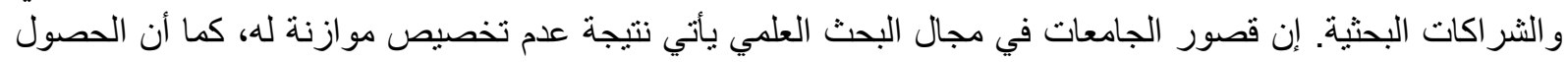

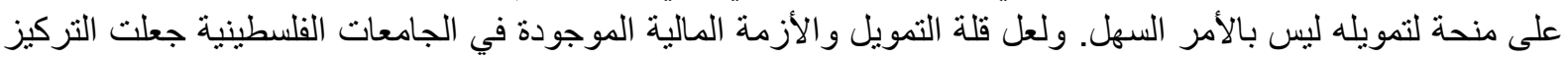
ينصب على التدريس أكثر من الأبحاث.

1.1 مشكلة الدراسة:

تعاني الجامعات العامة الفلسطينية من أزمة تمويل في السنوات الأخيرة تعود اللعو امل السياسية والاقتصادية المتغيرة مما أدى إلى وجود أزمات مالية خانقة أدت إلى التأثير سلباً على أداء الجامعات العامة الفلسطينية من هنا تتمثل مشكلة الدر اسة التها

في الإجابة عن الأسئلة التالية:

1. ما مدى استدامة مصادر تمويل التعليم في الجامعات العامة الفلسطينية؟

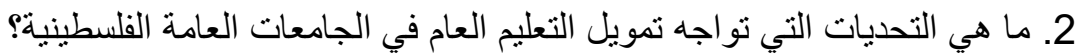
3. ماهي الفرص التمويلية الكامنة التي يمكن أن تستفيد منها الجامي التهات التهات العامة الفلسطينية؟

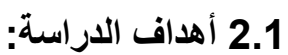

تهدف هذه الدر اسة إلى ما يلي:

1. التعرف على مدى استدامة مصادر التمويل في الجامع التعات التهات العامة الفلسطينية.

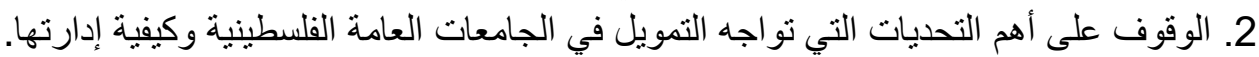

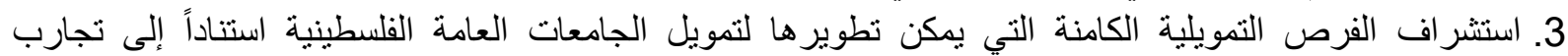

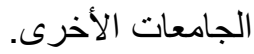


1. قد تفيد هذه الدر اسة المسؤولين عن مصادر التمويل في كيفية إدارة التحديات التي تو اجه التمويل في الجامعات العامة الفلسطينية

2. تسعى الدر اسة الحالية إلى استشر اف مصادر تمويل بديلة تُسهم في الارتقاء بالجامعات العامة الفلسطينية.

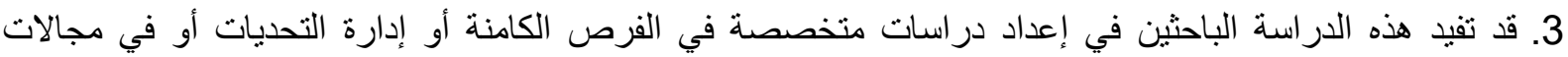
أخرى ذات علاقة بتمويل الجامعات العامة الفلسطينية.

4.1 مصطحات الاراسة:

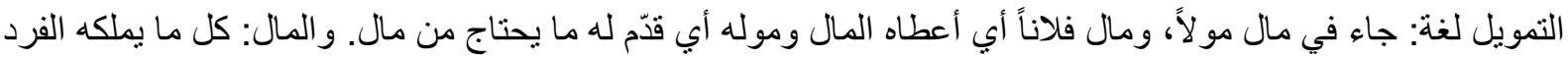

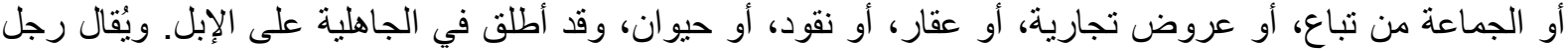

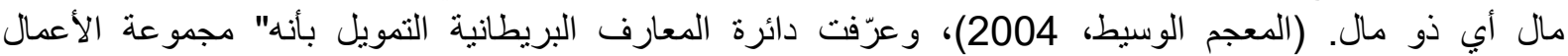
و التصر فات التي تمدّنا بوسائل الدفع". تمويل التعليم: مجموعة الموارد المالية المرصودة للمؤسسات التعليمية لتحقيق أهداف محددة و إدارتها بكفاءة عالية، وهو محاولة لتدبير الاحتباجات المالية اللازمة لتتفيذ خطة التعليم خلال مدة زمنية محددة. (الحربي، 2015).

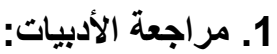

1.2

1.1.2. الاتجاهات المُعاصرة في تمويل التعليم الجامعي في الدول الأجنبية: 1.1.1.2 تمويل التعليم الجامعي في ألمانيا:

يُعد تمويل التعليم في ألمانبا مسؤولية مشتركة بين الدولة (الحكومة الاتحادية) والولايات الألمانية، وقد حدد الدستور

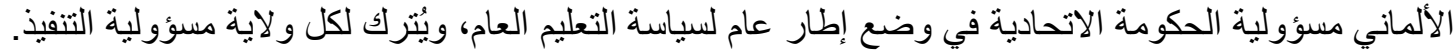

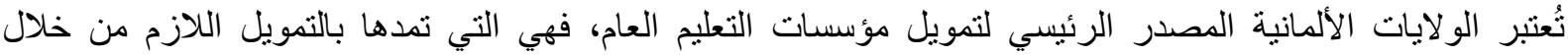

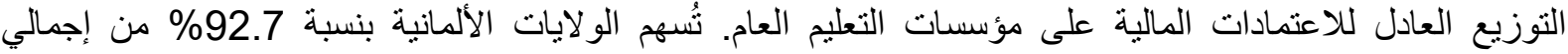
الموازنة المُخصصة للتعليم العالي. كما تُساهم الحكومة الفيدرالية بنسبة كبيرة في تمويل إنشاء وتشيبيد المباني الجديدة

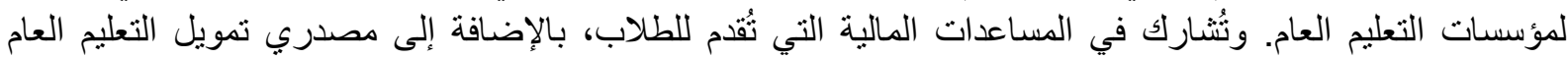

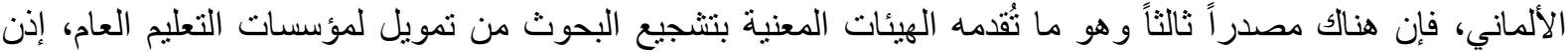

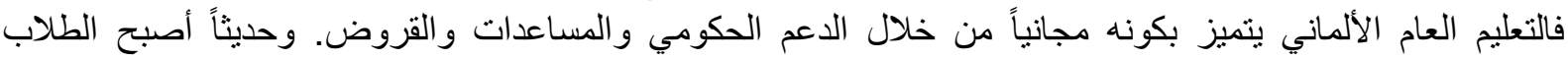
مُطالبين بسداد جزء من القروض المقدمة لهم. لهريز 2.1.1.2 تمويل التعليم الجامعي في بريطانيا:

تقع مسؤولية تمويل التعليم العام على عاتق الحكومة المركزية التي تُقدم منحاً مالية للجامعات البريطانية.

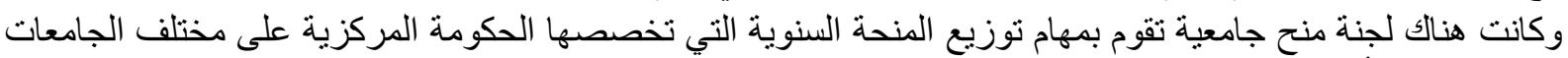

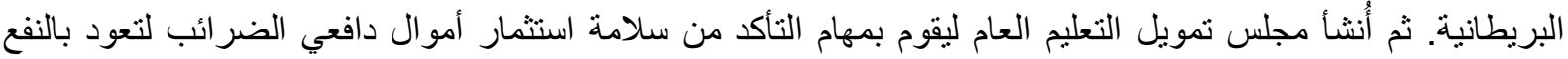

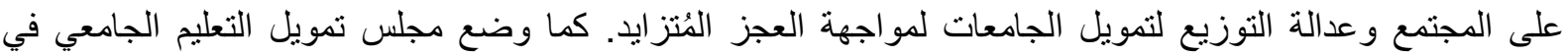

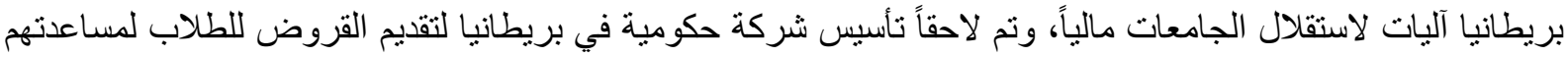
في مُو اصلة تعليمهم الجامعي، و عملت شروط للإقر اض و على الطلاب سدادها ضمن آلية مُنفق عليها. 3.1.1.2 تمويل التعليم الجامعي في اليابان: تُشسارك السلطات المحلية البلدية الحكومية المركزية في تمويل التعليم العام والجامعي، حيث تقدم الدعم المادي للمؤسسات

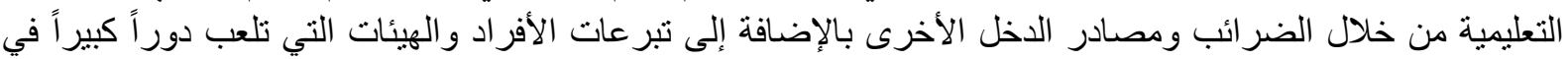
تمويل التعليم الجامعي. وهناللك القروض الطلابية من خلال المنح يتم سدادها بعد تخرجهم. ومن خلال الاتجاهات الحديثة 
السابقة لتمويل التعليم العام الجامعي في بعض الدول تتضح المصادر التالية: الحكومات المركزية، حكومات المحليات

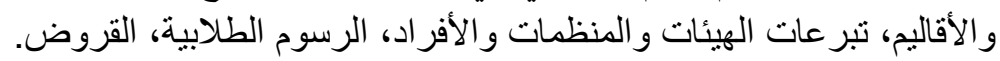

2.1.2 تمويل التطليم العام في الدول العربية:

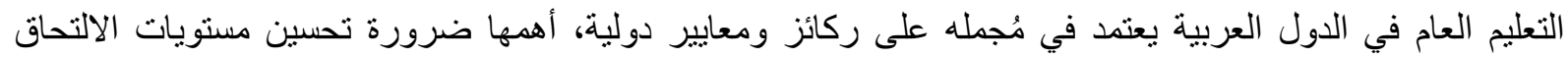

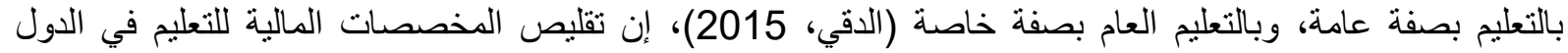

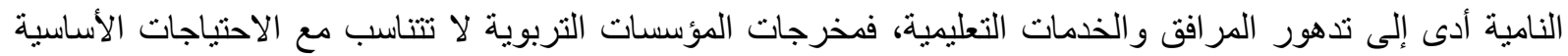
للتنمية الاقتصادية والاجتماعية (الأنصاري، 2002)، تشترك الدول العربية في اعتمادها على الدعم الحكومي لتمويل

التعليم العام بتفاوت بسيط بالنسب يعود إلى النظام التعليمي السائد. وقد قسّم (شاهين...) الدول العادية العربية إلى مجمو عنين:

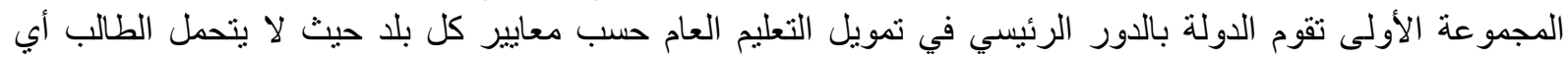

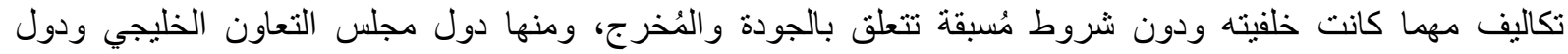

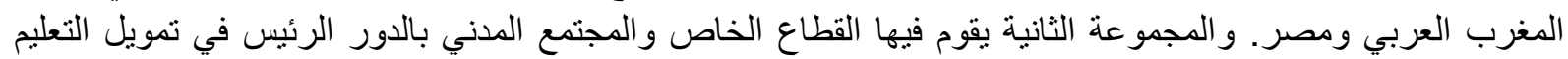
العام، ومنها الأردن وفلسطين ولبنان.

وفي در اسة قياس متغير ات تمويل التعليم العام بالجزائر، قسّمت الدر اسة مصادر التمويل للتعليم العالي إلى نو عين:

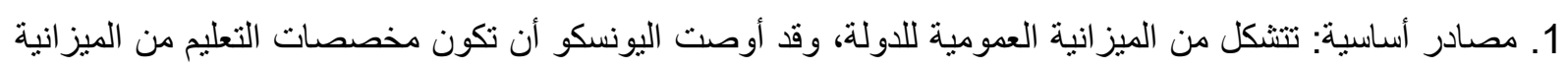

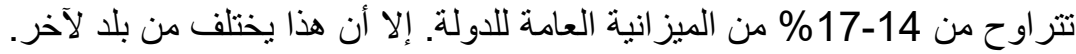

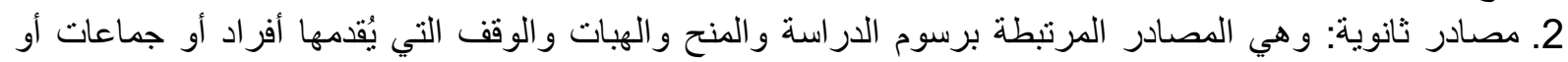

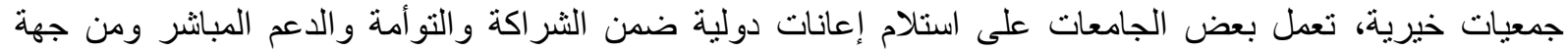

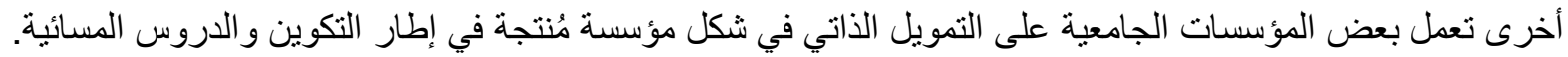

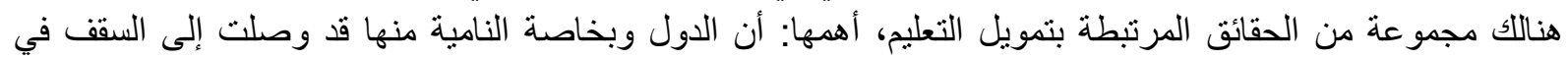

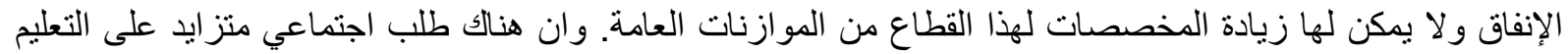

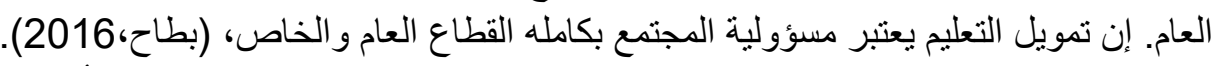

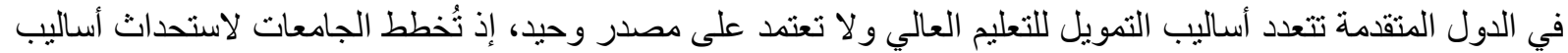

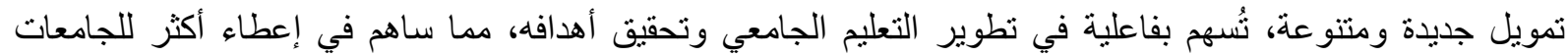

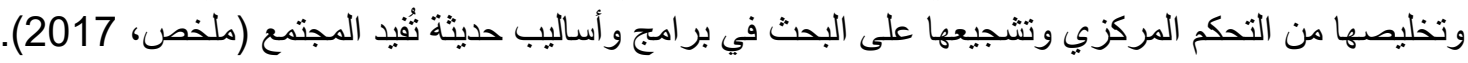

2.1 .3 خطوات التخطيط لتمويل التعليم العام، وتثثمل الخطوات التالية (النعمي،2015)

1. المسح الثامل للموارد الحقيقية على مستوى الدولة، وتحليل البيانات الخاصة بالنفقات، أب جملة الاعتمادات المالية

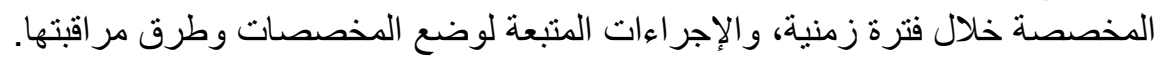

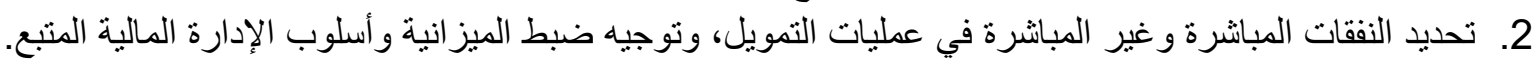

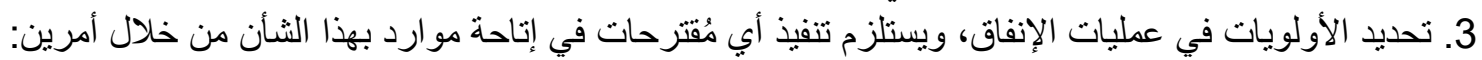

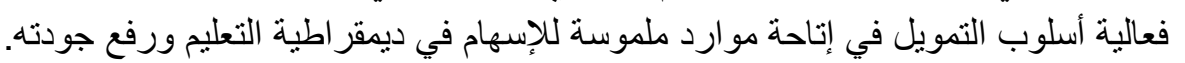

الواقعية و إمكانيات النطبيق العملي.

4. تحديد إيجابيات وسلبيات كل وسيلة جديدة تستخدم في تمويل التعليم الجامعي واتخاذ القرار في ضوء المخاطرة المحسوبية و المقبولة لكل أسلوب من أساليب التمويل. 5. تحديد مصادر التمويل الجامعي ومدى قدرتها على تحمل النفقات سواء كان المصدر الطالب أم الدولة.

2.1 .4 مُعوقات الاستثمار في التعليم العالي (الغافري، 2005)

معوقات اقتصادية، إذ يعتبر الوضع الاقتصادي من أهم المعوقات فغالبية المشكلات تعود إلى قلة المخصصات المالية

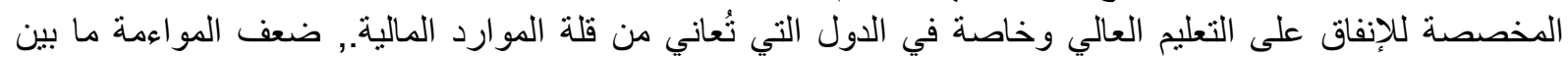

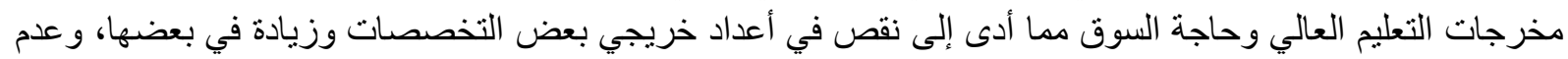

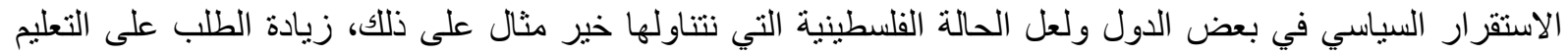

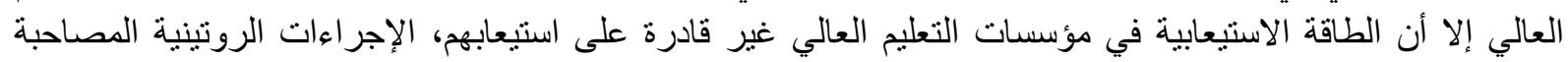


للاستثمار في مؤسسات التعليم العالي مما يُضعف إقبال المستثمرين على الاستثمار في مجال التعليم، الرسوم المرتفعة

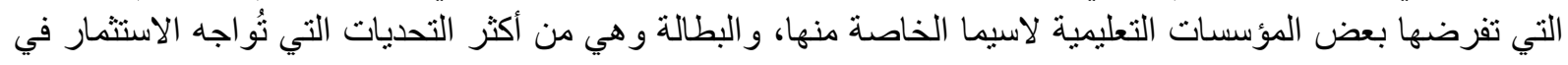

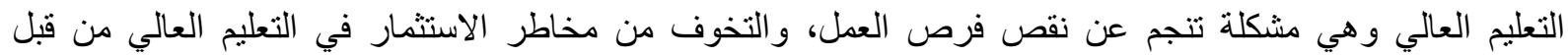

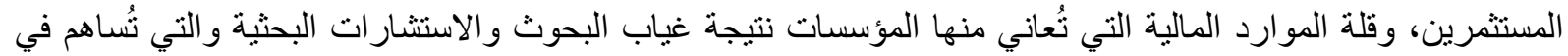
توفير مصادر دخل إضافية للمؤسسات التعليمية الجامعية الخاصة.

2.1 .5

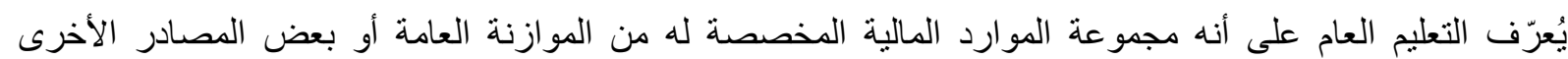

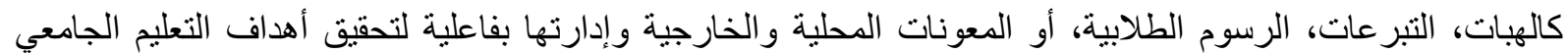

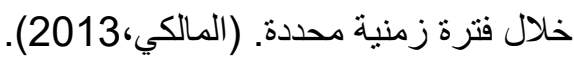
تعتمد فلسطين منهجاً توفيقياً في التمويل يقوم على إثر الك كل الجهات المعنية في تحمل تكاليف التعليم ما بين القطاع العام

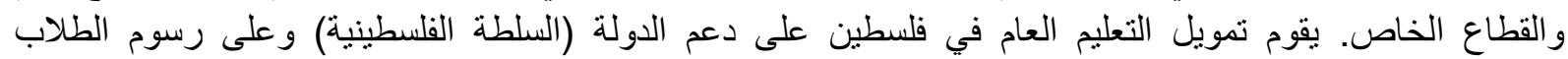

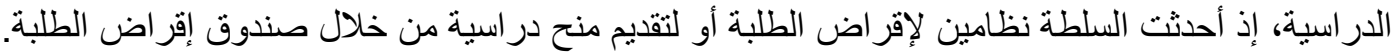

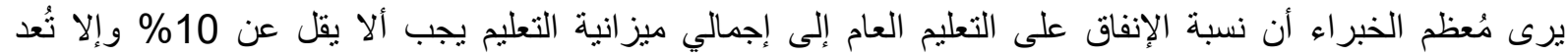

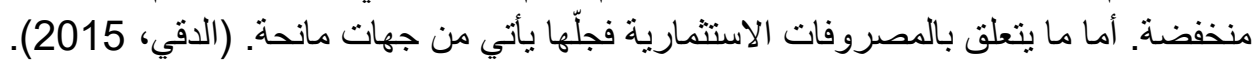

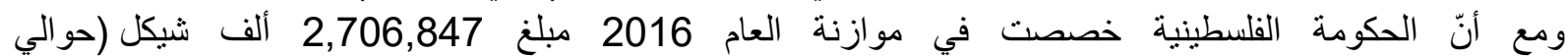

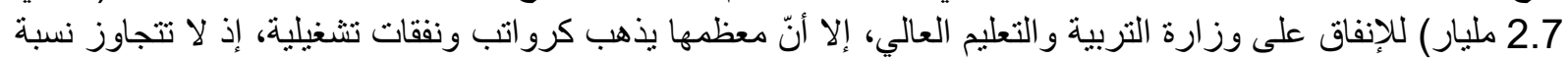
النفقات التطويرية 1.8\% من الميزانية المخصصة للوزارة التي تشكل 18.36\% من مجموع النفقات العامة البالغة

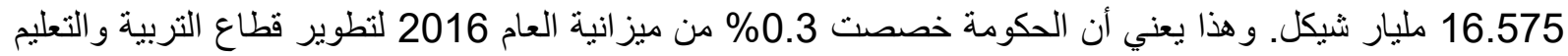

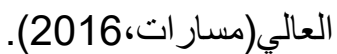

ولعل العجز المالي المتر اكم على الجامعات الفلسطينية يرجع لعدم وجود سياسة تمويلية واضحة للتعليم العالي.

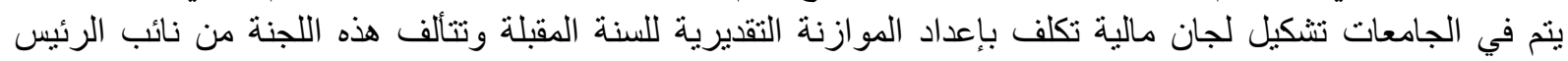

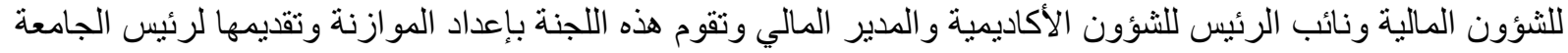

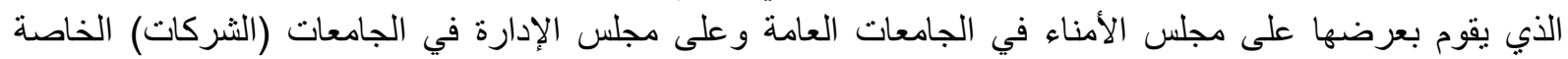
لاعتمادها بشكل نهائي . (Ann, 2009).

\subsection{6 أزمة تمويل التعليم في الجامعات العامة الفلسطينية:}

تكمن أزمة التعليم في الجامعات العامة الفلسطينية كما جاء في دراسة لمعهذ ماس عام 2011 بما يلي:

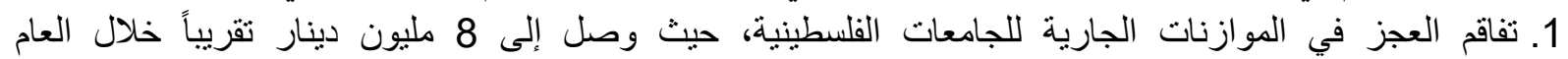

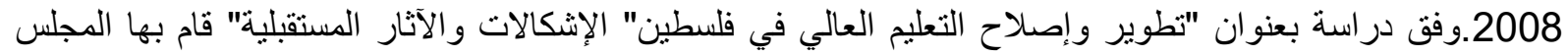

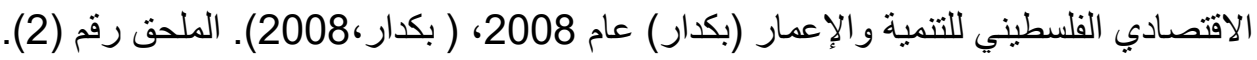

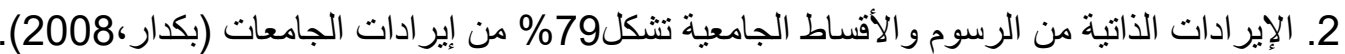

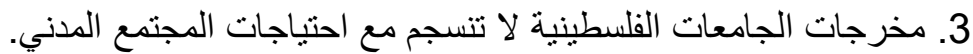

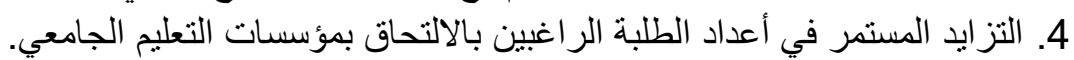

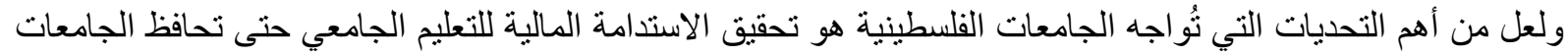

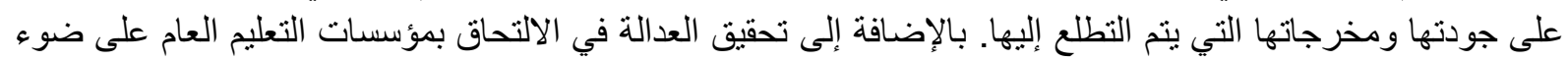

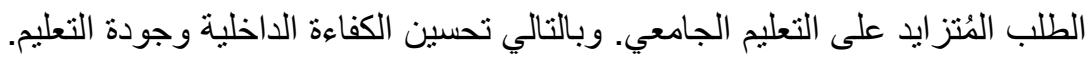

2.2

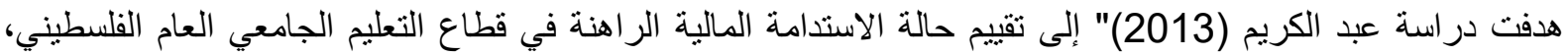

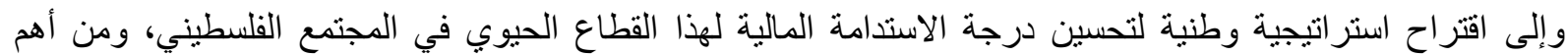

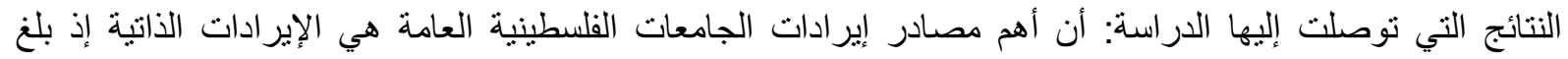
مجموع الإيرادات في (9) جامعات عامة (107) مليون دينار، والمصدر الثاني هو المنح والهبات إذ التتوجه هذه المنح 
نحو النقات التطويرية (المباني) و المصدر الثالث هو قروض الطلبة، حيث بلغ رصيد هذه القروض (72) مليون في

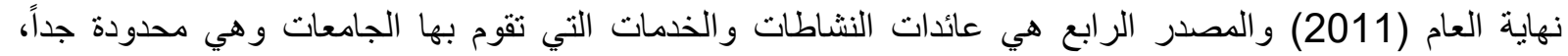

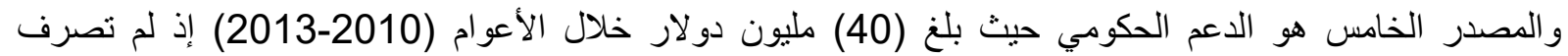

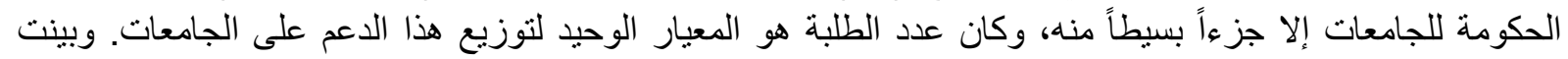

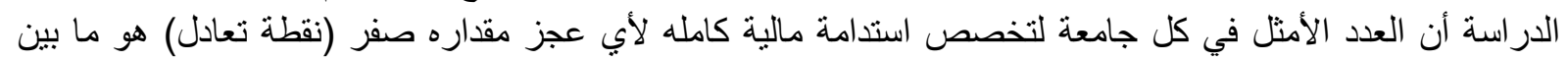

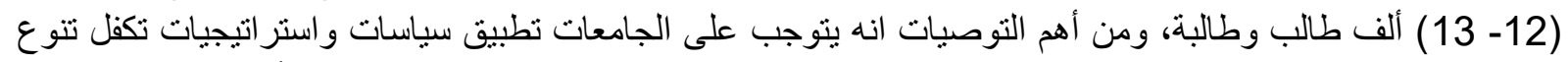

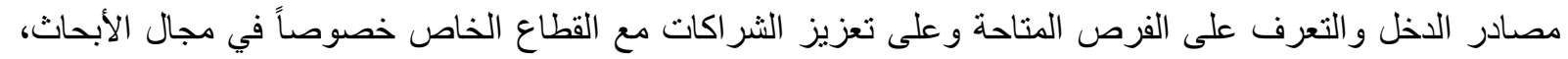

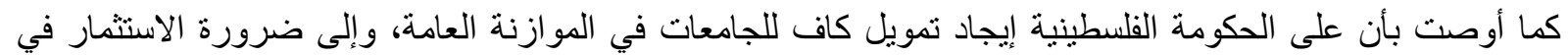
التدريب على المهار ات القيادية التنموية لقيادات التعليم العالي، و إلى وضع سيانية كاستات تمويلية تساعد في تحقيق الاستدامة

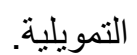

و هدفت در اسة البلتاجي (2015) إلى نسليط الضوء على الجى قضية تمويل التعليم العام في مصر ومحاولة التصدي للمشاكل

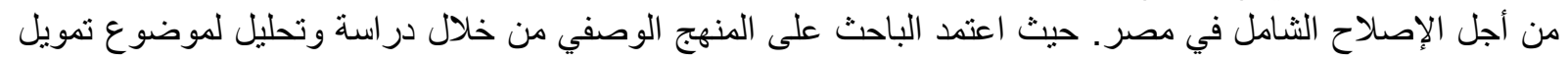

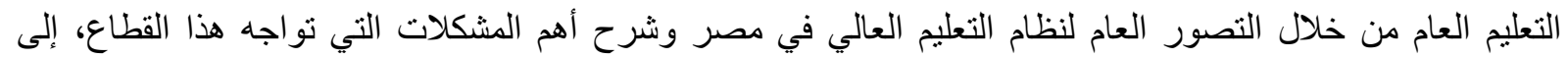

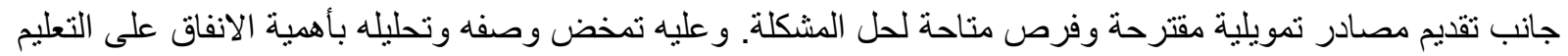

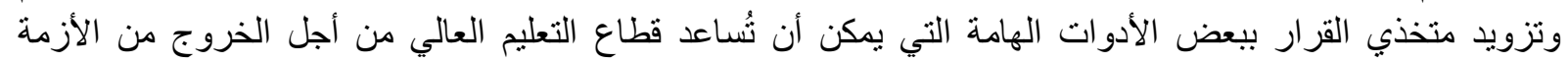

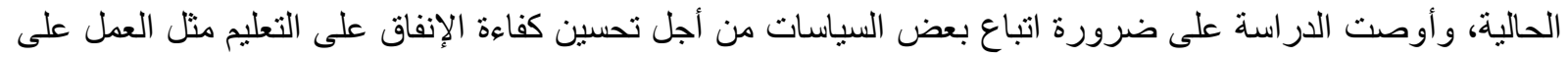

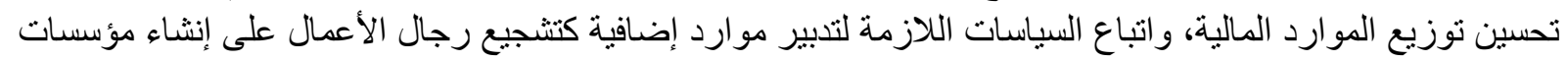

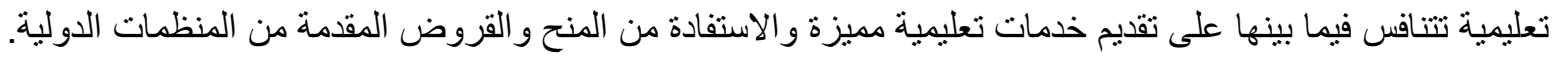

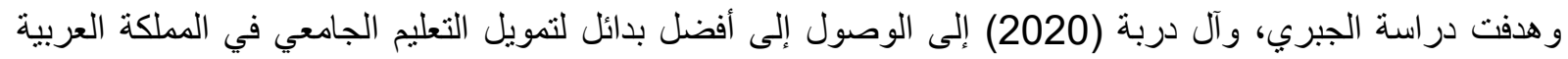

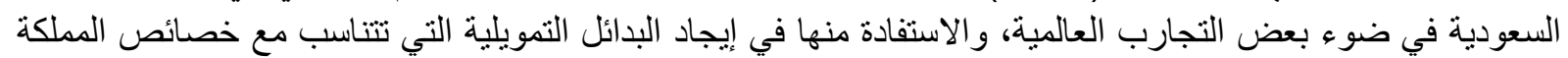

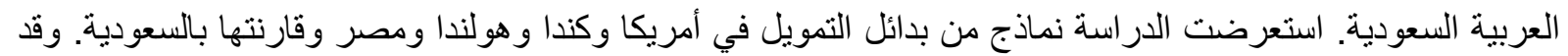

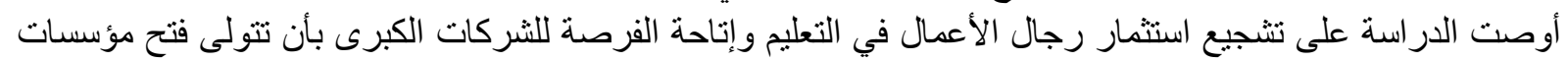

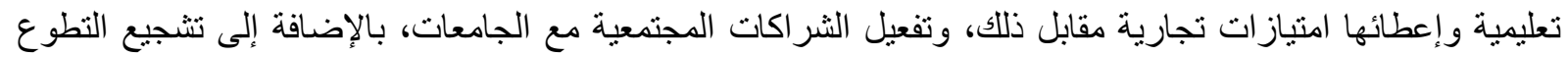

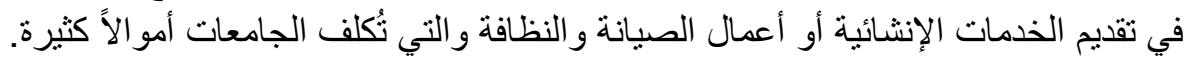

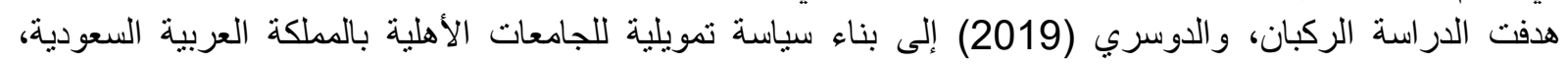

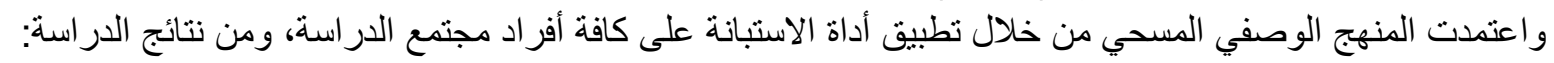

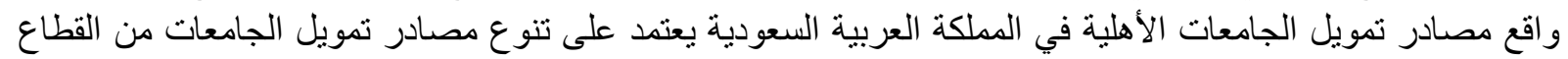

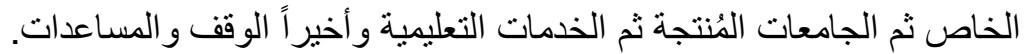

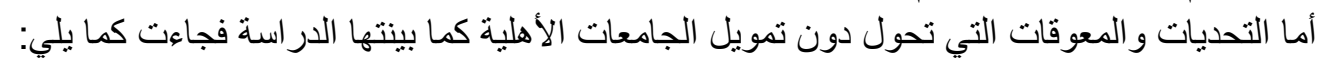

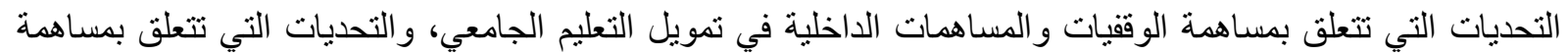

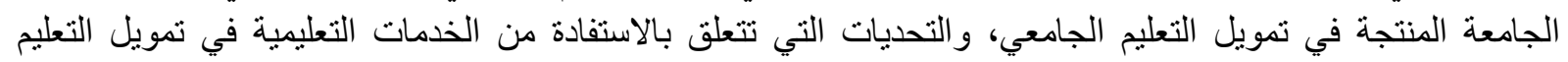

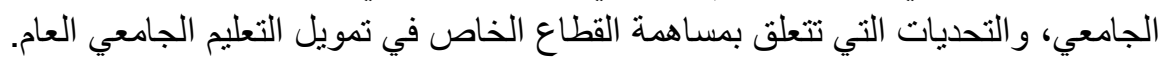

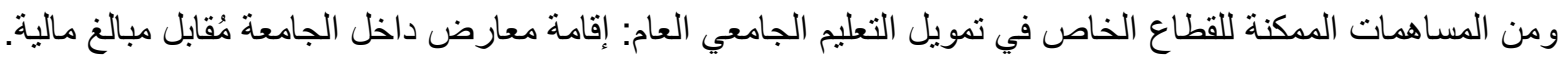

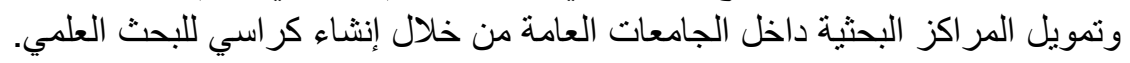

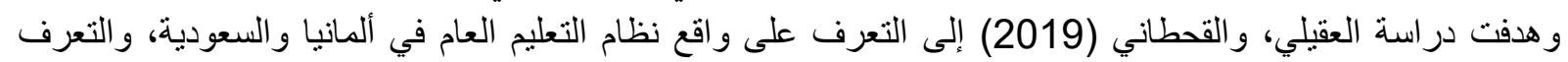

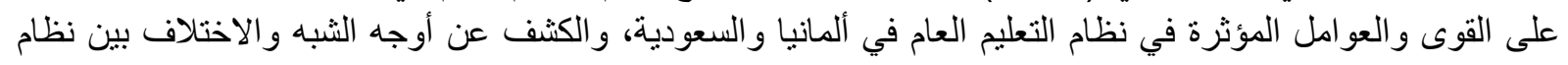

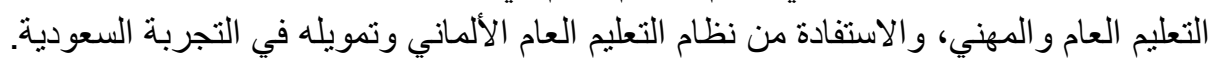

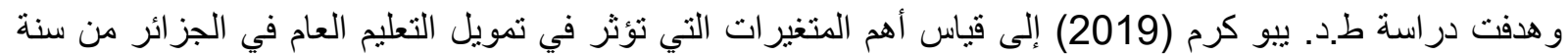

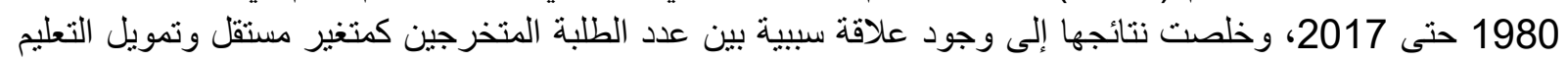

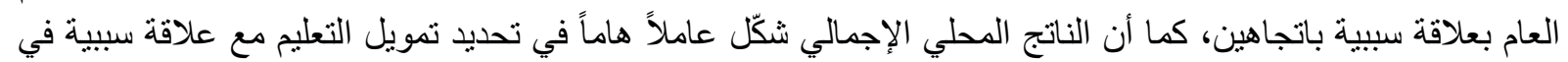

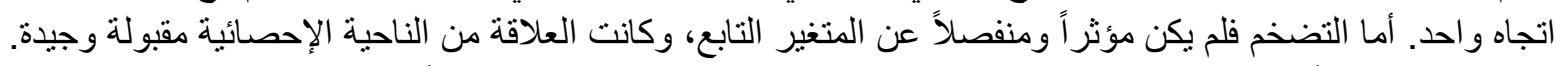

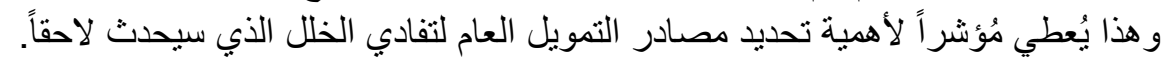

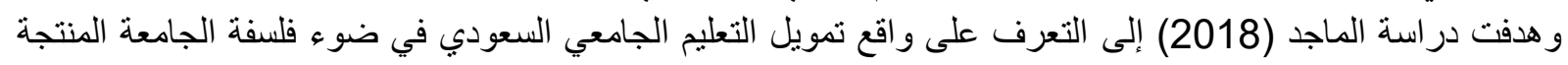
و الكثف عن معوقات ذلك للوقوف على متطلبات تطوير التمويل، ثم التعرف على التى أبرز التجارب التعاب العالمية والعربية 
و المحلية للوصول إلى مقترح لتمويل الجامعات السعودية في ضوء فلسفة الجامعة المنتجة. اعتمدت الدراسة المنهج

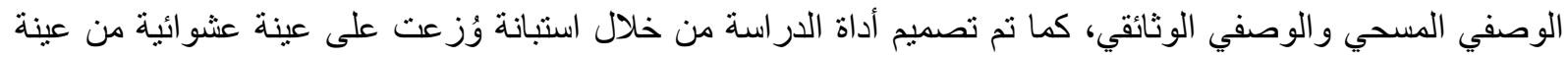

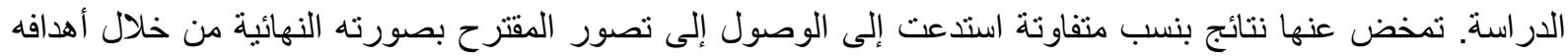

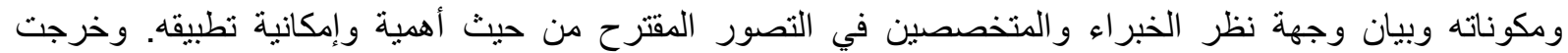

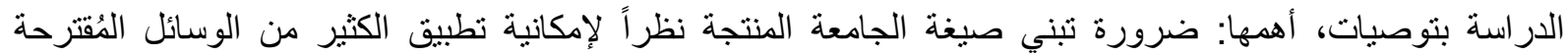

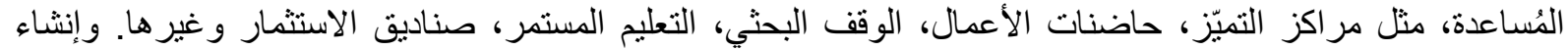

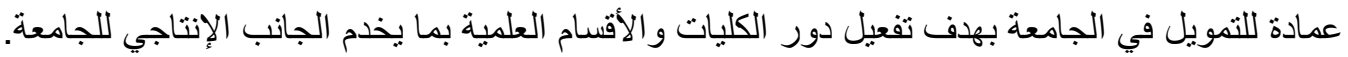

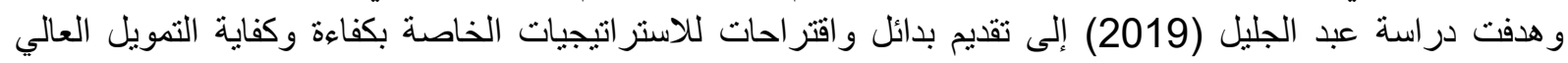

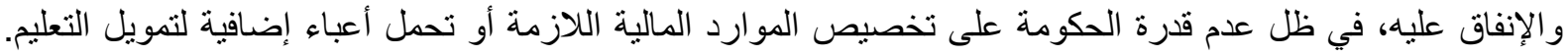

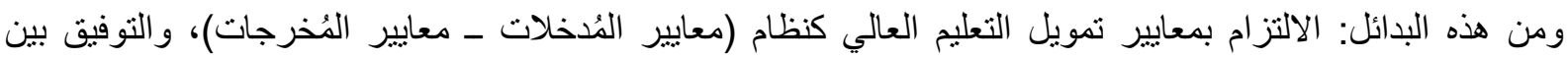

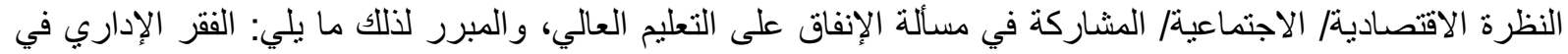

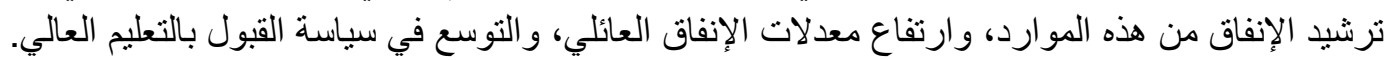

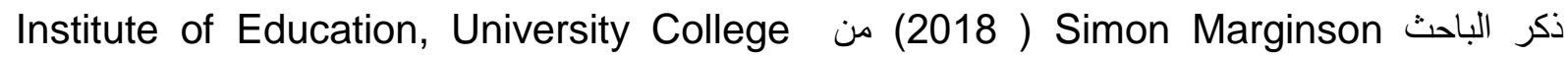
في دراسته بعنوان" الاتجاهات العالمية في تمويل التعليم العالي: المملكة المتحدة" عام 2018 التطام (Global trends in higher education financing: The United Kingdom)

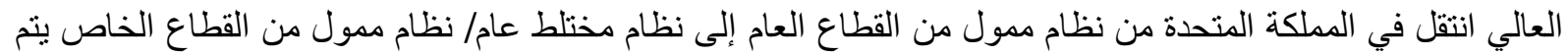

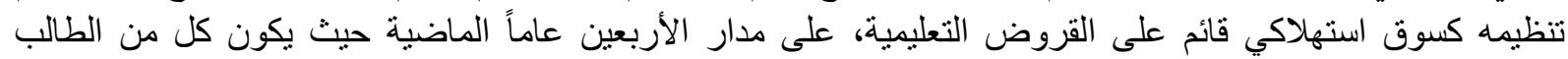

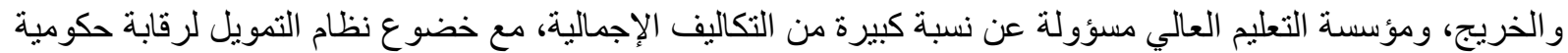

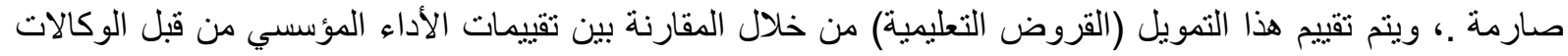

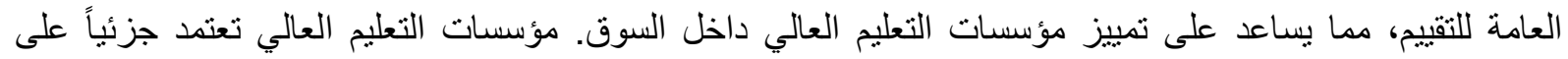
التمويل الحكومي في أشكال الدعم المرتبط بالبحث و إعانات التعليم ودعم نظام القروض في في حالة عدم سداد الديون.

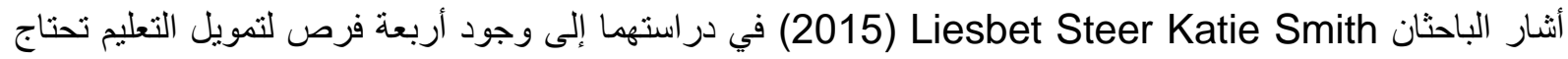
إلى جهذ وعمل على مستوى عالمي (1) إنشاء هيئة عالمية متخصصة بالاستثمار في التعليم تعمل الهيئة على تقديم

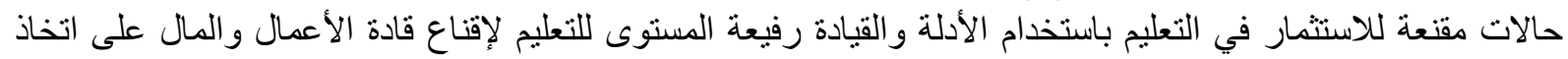

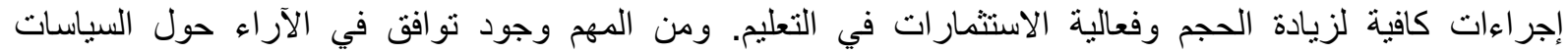

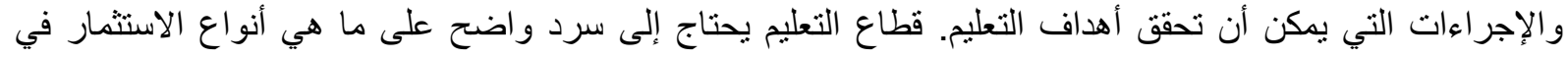

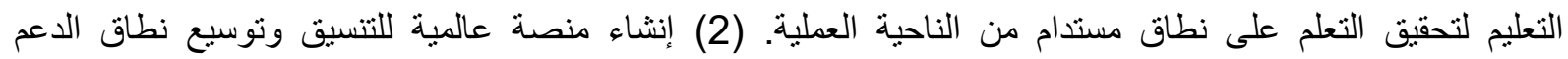

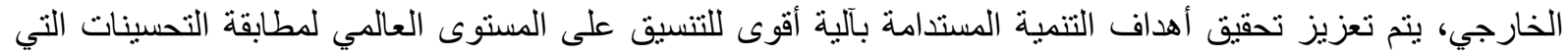

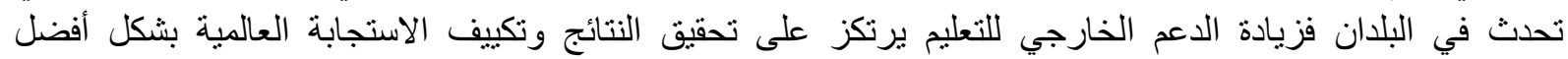

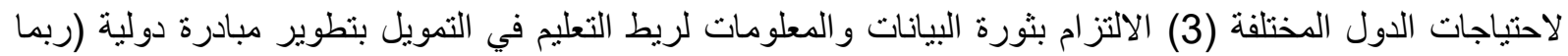

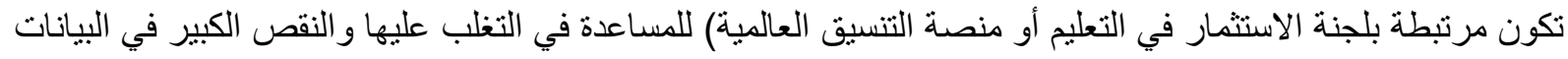

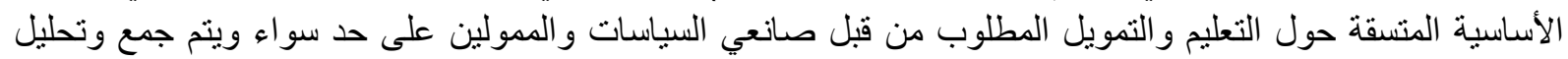

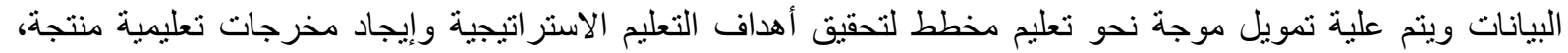

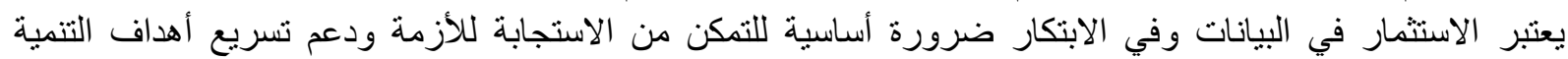

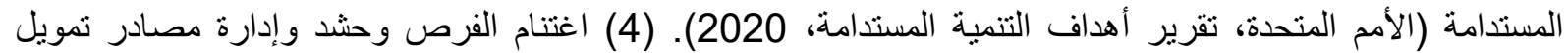

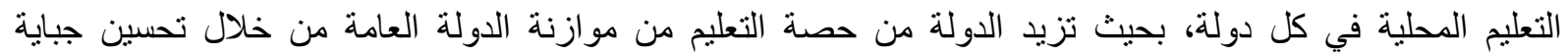
الضر ائب لزيادة الإيرادات. (Steer and Smith,2015).

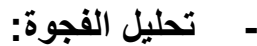

ما يميز هذه الدراسة عن الدراسات السابقة في أنها تُقدم تصور اً عملياً لتطوير مصادر التمويل الحالية حتى تُصبح مصادر التهار

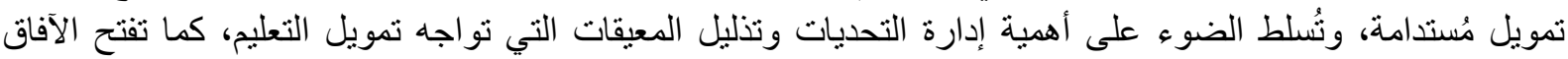

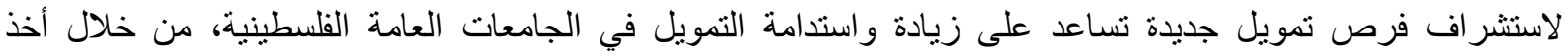

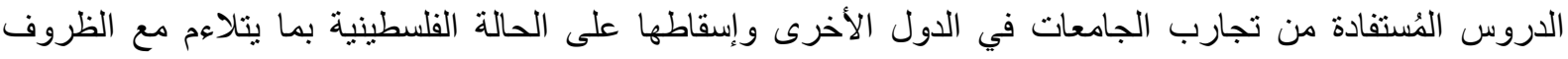

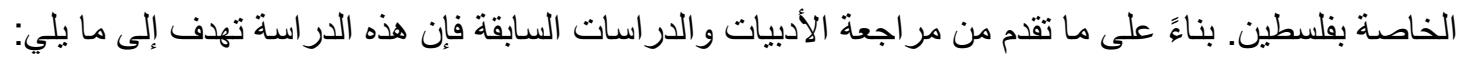


-التعرف إلى مدى استدامة مصادر التمويل في الجامعات العامة الفلسطينية.

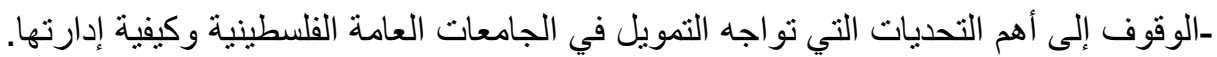

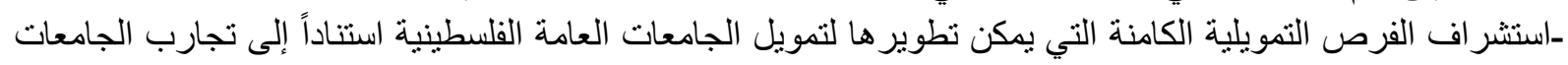
الأخرى.

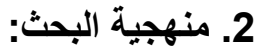

تستخدم الدر اسة أسلوب المنهج الكيفي التحليلي، لمناسبته لطبيعة الدراسة و أهدافها.

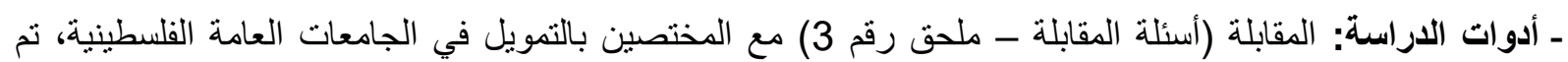

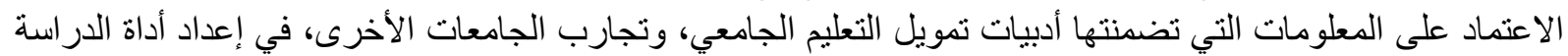

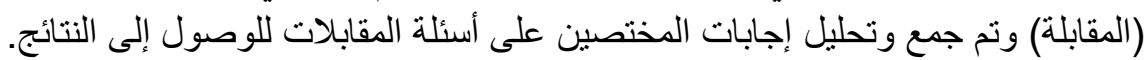

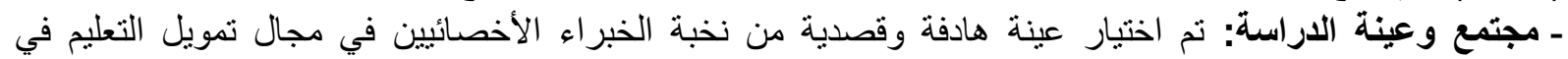
الجامعات العامة الفلسطينية بناء على معايير من أهمها التخصص، وسنة وسنوات اتل الخبرة، وبلغ عددهم (8) مختصين بالتمويل. (ملحق رقم 4: أسماء المتقابلين)

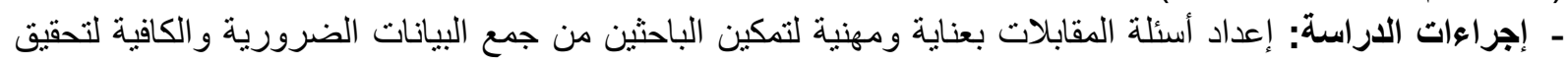

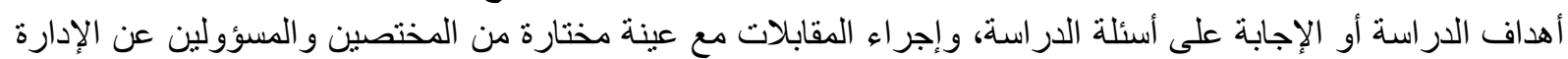

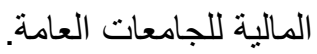

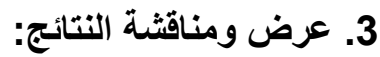

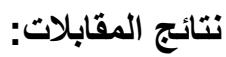

كانت نتائج إجابات المختصين بالتمويل عن أسئلة الدراسة على النحو الآتي:

- ـ المحور الأول مصادر تمويل التعليم في الجامعات العامة الفلسطينية؟ وما مدى استدامة مصادر التمويل الحالية؟

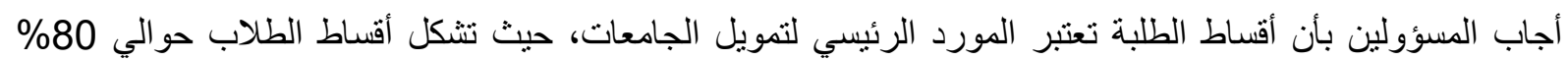

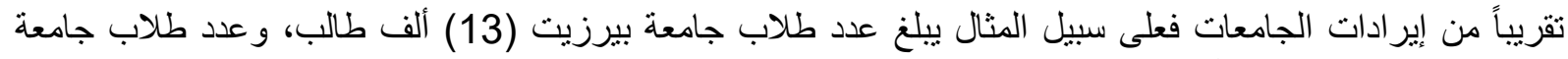

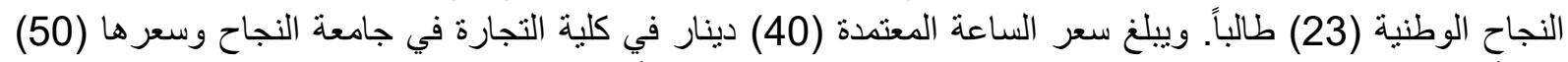

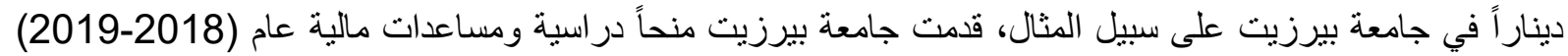

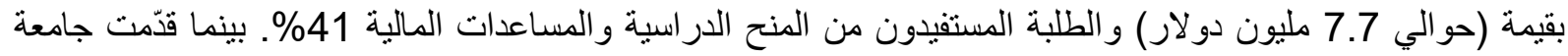

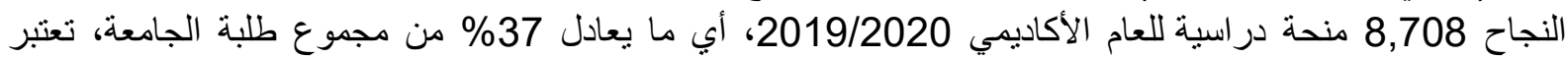

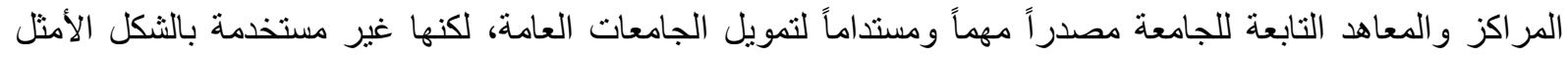

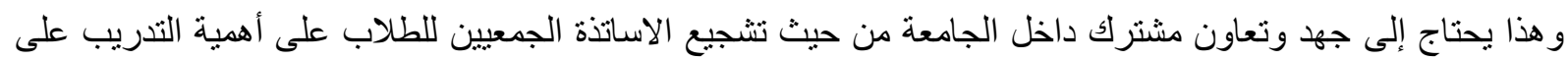

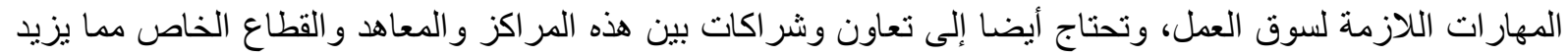

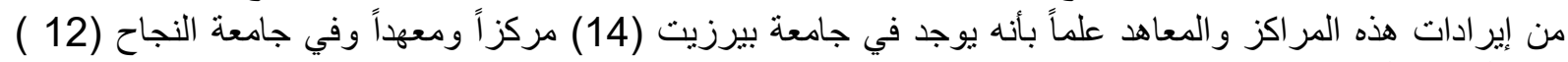

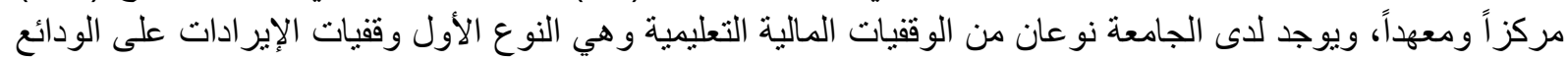

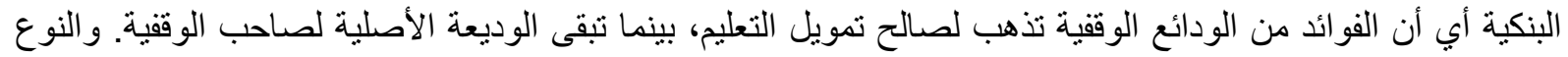

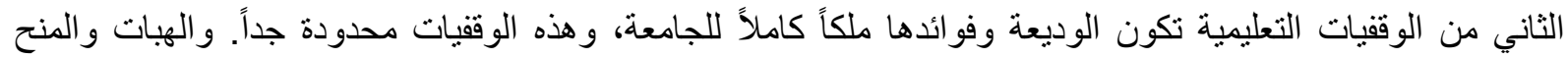

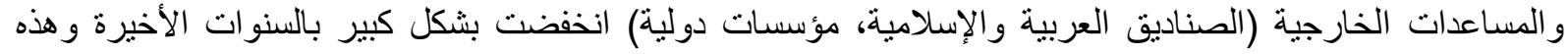

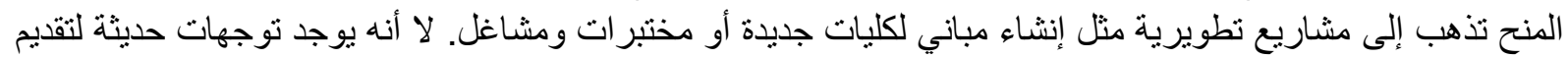

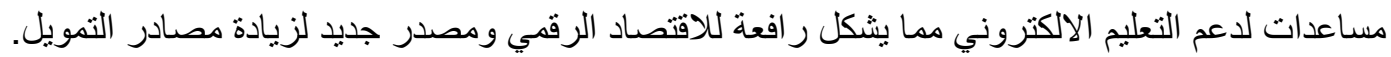

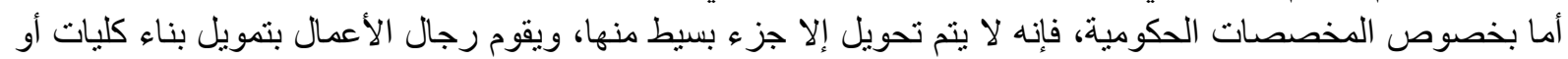

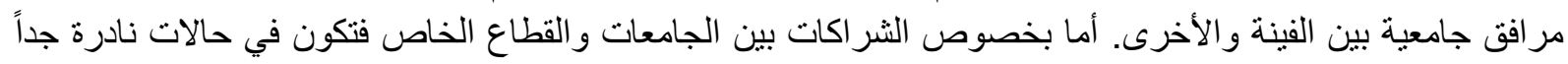
ولا يوجد تسويق أو استثمار في الأبحاث الصادرة عن الجامعة أو بيع براءات اختر الفئ أو أو مُلكيات فكرية. 
المحور الثاني: التحديات التي تواجه تمويل الجامعات العامة الفلسطينية؟ وكيف يتم إدارتها؟ أجاب المختصون على أن التحديات التي نواجه تمويل الجامعات العامة الفلسطينية تكمن في أن قطاع التعليم العالي في

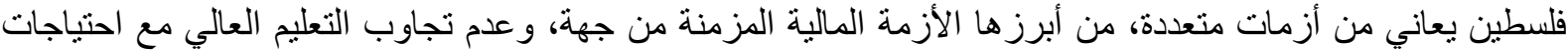

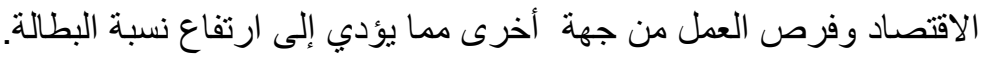

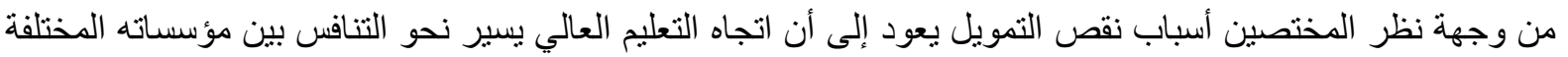
بدلاً من التكامل الوطني. ويوجد تدنِي في المستويات الأكاديمية وتضخم هائل في عدد المؤسسات و أعداد الطلبة ونقص في التصاي

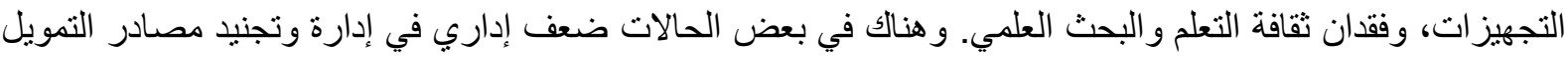
وطرق التعامل مع التحديات التي تو اجه التمويل.

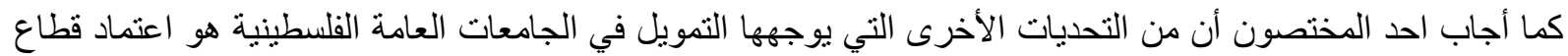
التعليم على المساعدات الخارجية المرتبطة بالوضع السياسي وبالأجندات السياسية لهذه الدول (التئمويل السياسي) وأيضا يرتبط بالوضع الاقتصادي لبعض الدول الأخرى، بالإضافة إلى ترتيب أولويات التمويل أو الدعم لهذه الدول بين صحة الدئ

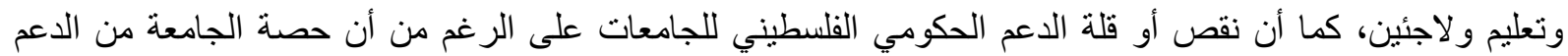

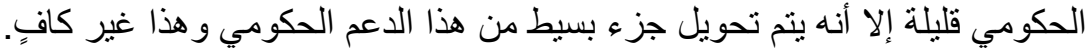

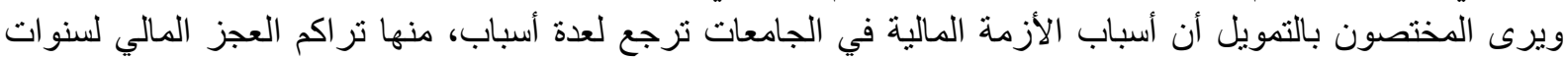

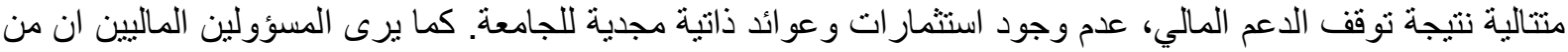

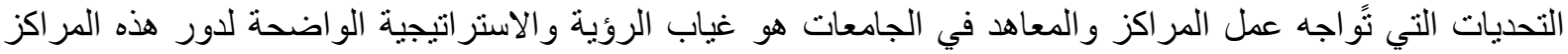

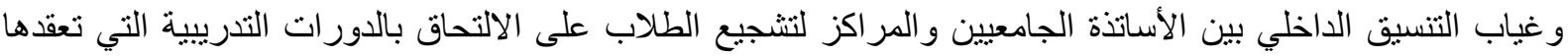

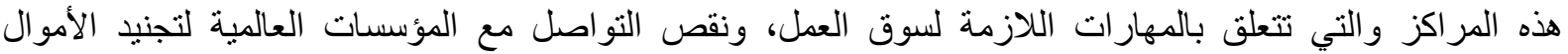

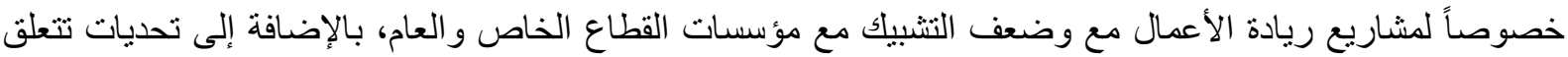

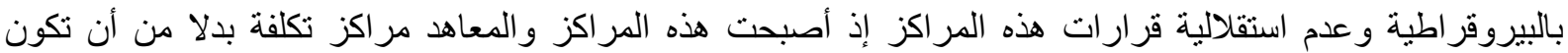
مر اكز إير ادات تعزز من مصنادر تمويل الجامعات.

المحور الثالث: الفرص التمويلية الكامنة التي يمكن أن تستفيل منها الجامعات العامة الفلسطينية استناداً إلى تجارب

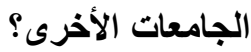

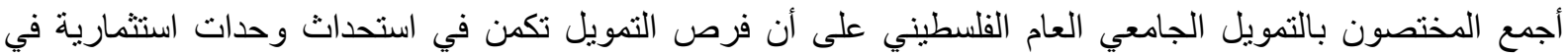

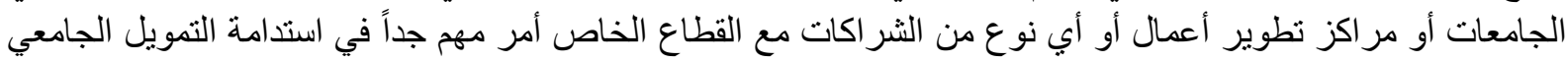

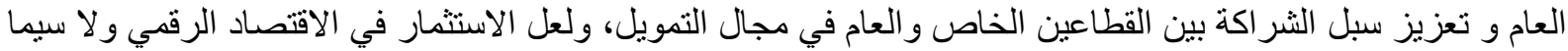

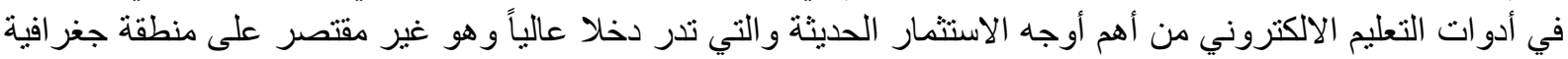

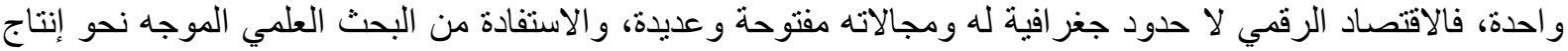

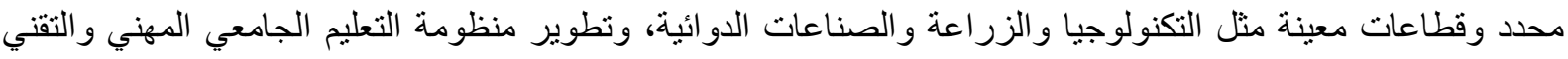

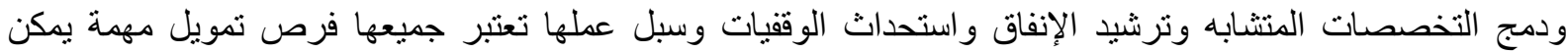

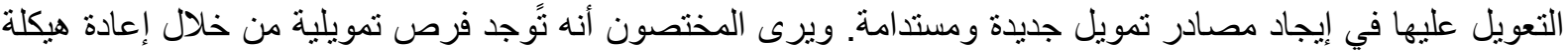

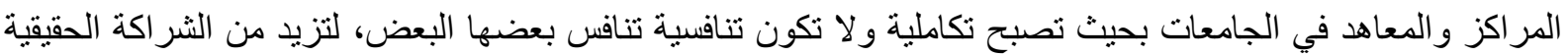

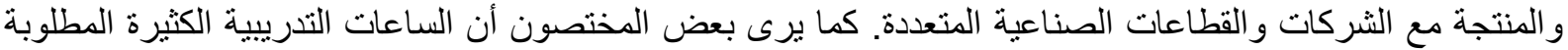

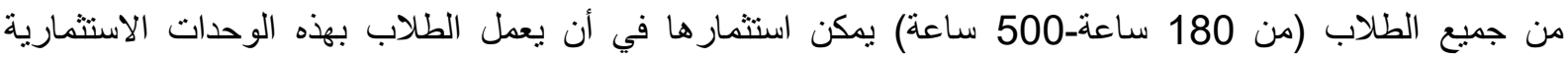

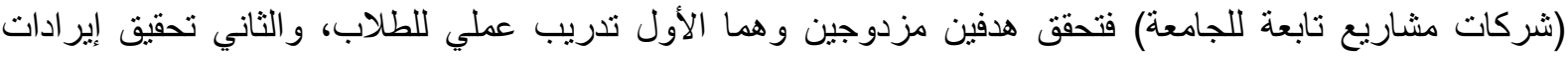

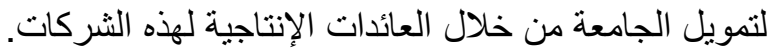

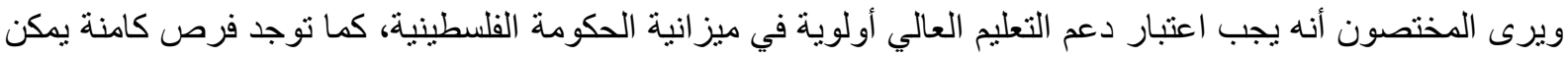
الوصول إليها من خلال رفع مستوى التشبيك بين الجامعات وخريجيها بعد التخرج، وكذللك رفع مستوى العلاقات و التبادل

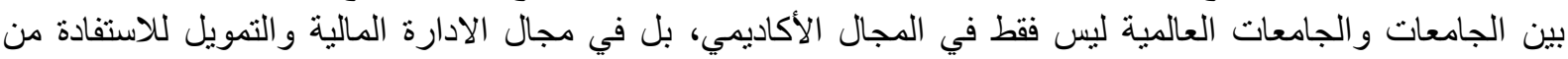
التجارب الناجحة لهذه الجامعات في مجال تطوير وتحسين مصادر التمويل المستدامة. 
بما أن زيادة الإير ادات يأتي بالدرجة الأولى من أقساط الطلبة، فإن الطريق إلى زيادة الإير ادات من الأقساط إما يأتي من

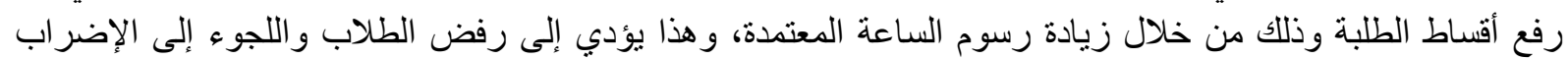

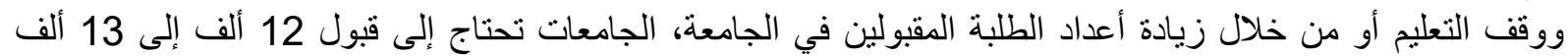

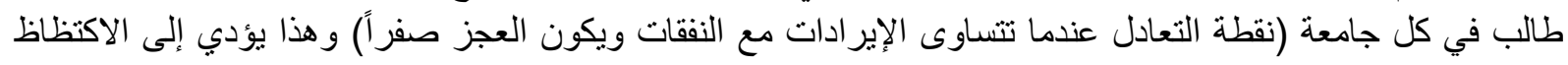

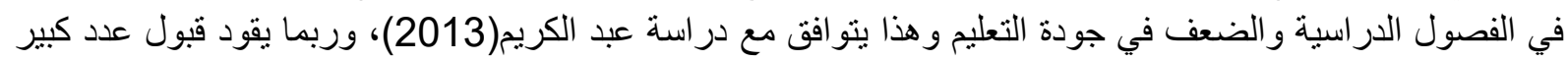

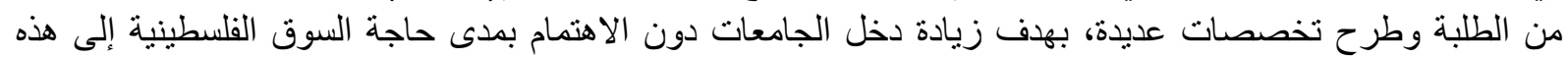

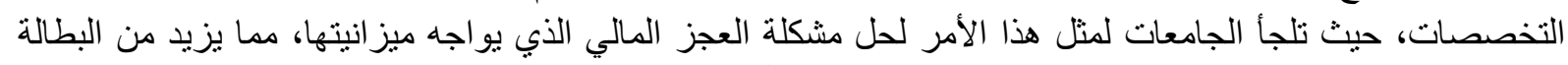

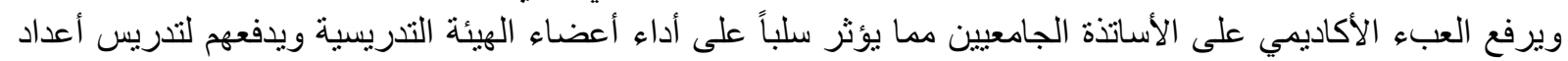

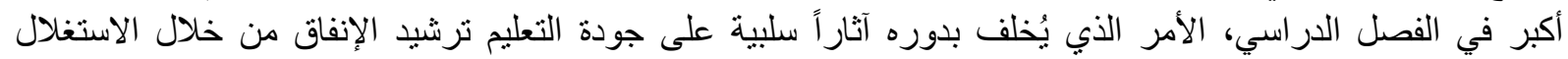

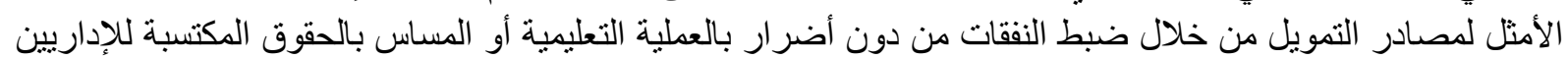

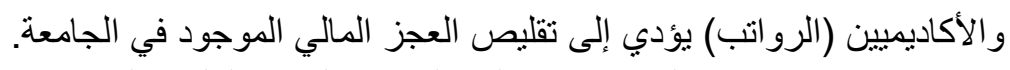

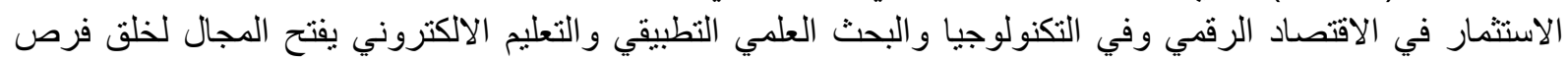

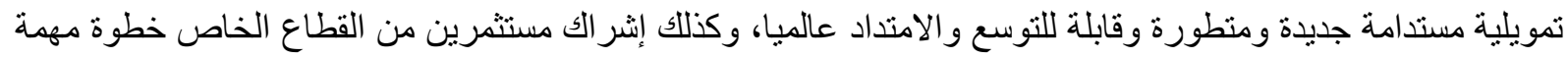

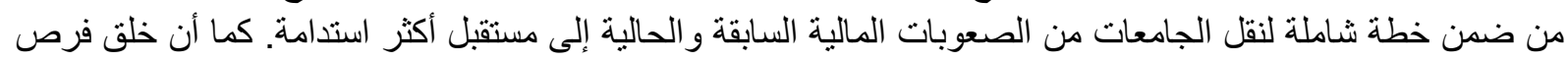

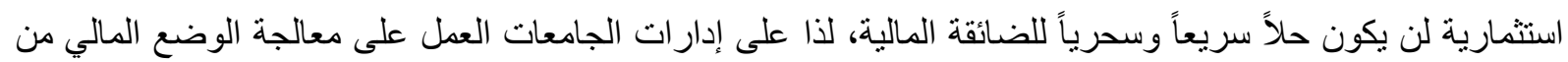

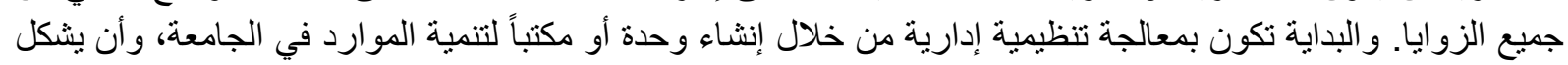

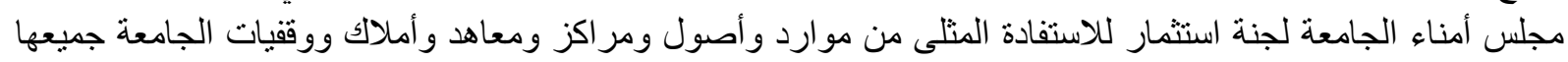

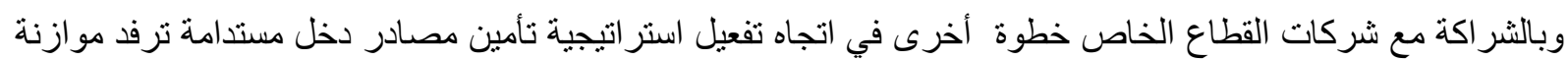

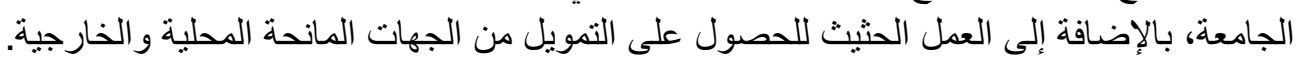

مناقثة النتائج المتعلقة بالمحور الثاني: التحديات التي تواجه تمويل التعليم العام في الجامعات العامة القلسطينية. يوجد تحديات ومعيقات نتيجة الظروف المحيطة فالعر اقيل التي يضعها الاحتلال الذي يعمل بشكل منو اصل على خلق

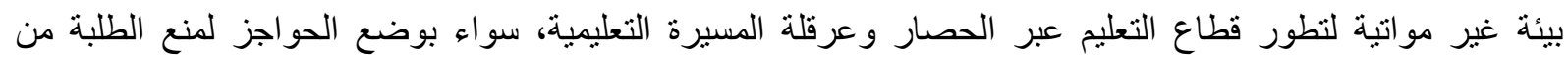

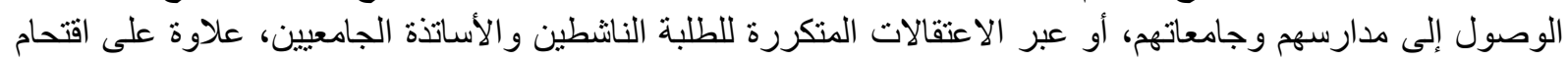

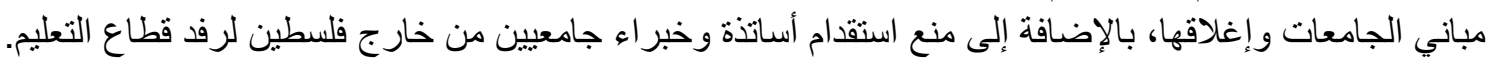

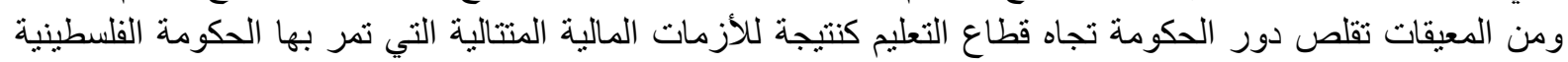

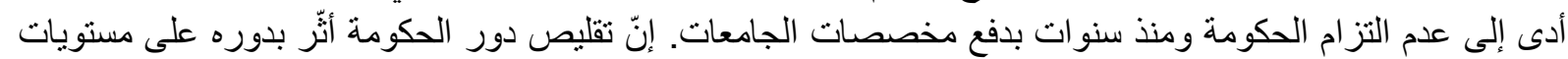

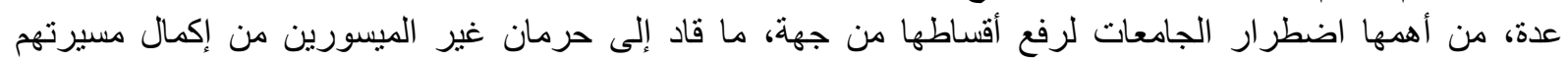

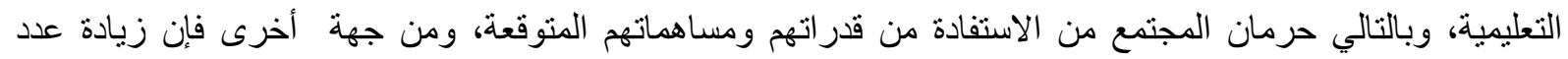

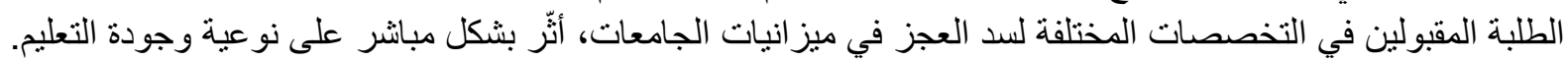

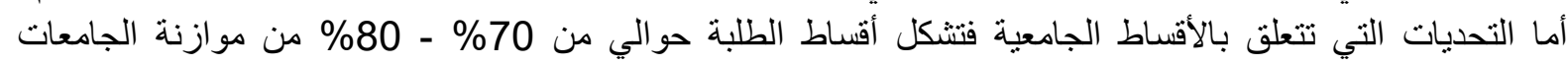

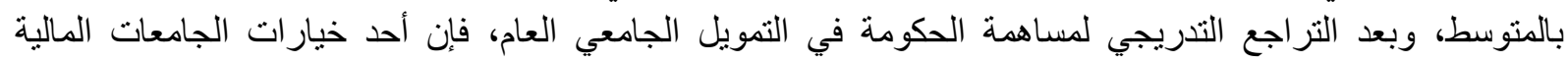

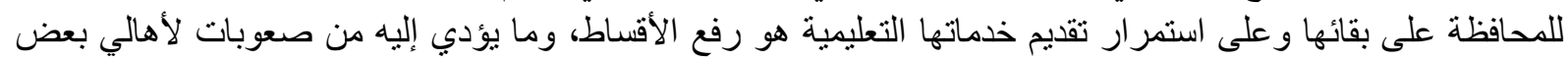

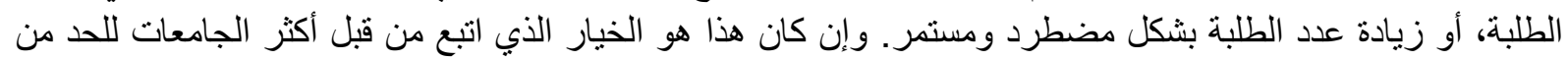

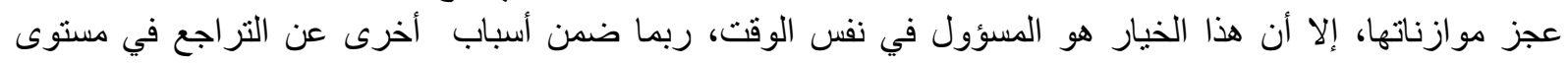

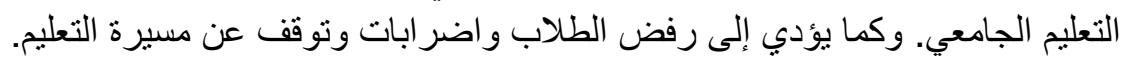

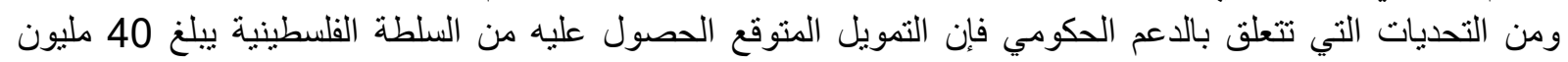

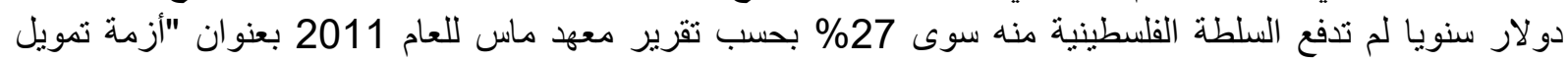
التعليم العالي في الأر اضي الفلسطينية"، (معهد ماس، لإ، 2011)، كل الجامعات تعجز عن تغطية الفرق بين النفقات الجارية 
و الأقساط لذلك فإن على الحكومة أن تسد هذا الفرق في موازنة الجامعة. لكن الحكومة الفلسطينية تعيش دائما في حالة من

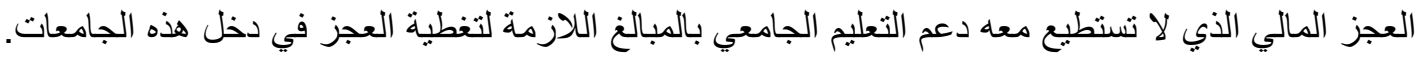

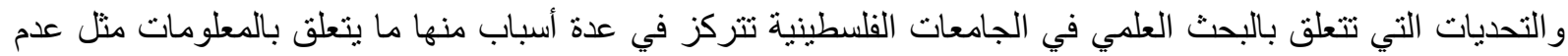
توفر الدوريات والمجلات المتخصصة. وعدم وجود شبكة معلومات عالمية وتقنية حديثة لاى المكتبات.

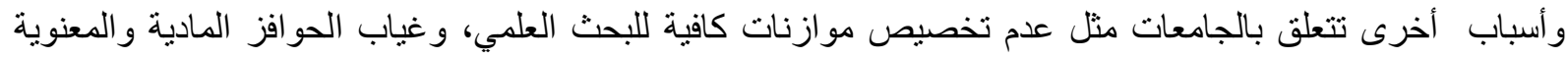

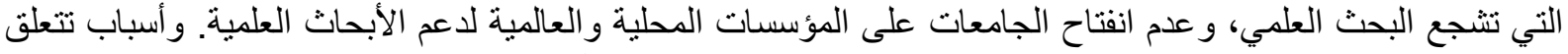

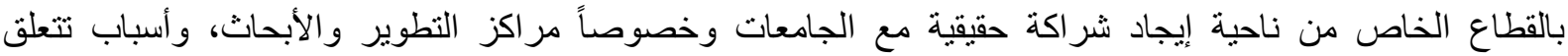

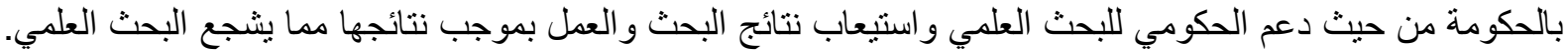

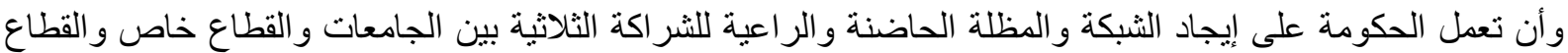

مناقشة النتائج المتعلقة بالمحور الثالث: الفرص التمويلية الكامنة التي يمكن أن تستفيد منها الجامعات العامة القلسطينية استناداً إلى تجارب الجنامعات بالمور الأخرى؟

يأتي إنشاء وحدات الاستثمار أو مراكز تطوير أعمال في الجامعات بهدف دراسة وتتمية وتطوير الاستثمار في مشاريع ذات مردود تجاري وبما ينسجم مع سياسة الاستثمار التي يقرر ها مجلس أمناء الجامعة، وكذللك ضمن التهن الأنظمة و التعليمات

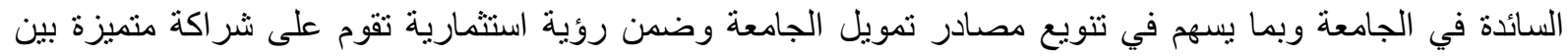

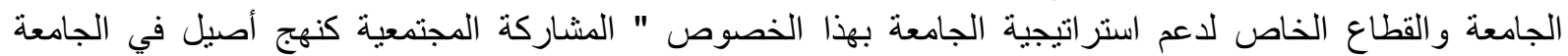
و المساهمة النشطة في تحقيق مصادر تمويل مستدامة للجامعة، وذلك من خلال: إيجاد فرص استثمارية جديدة للجامعة.

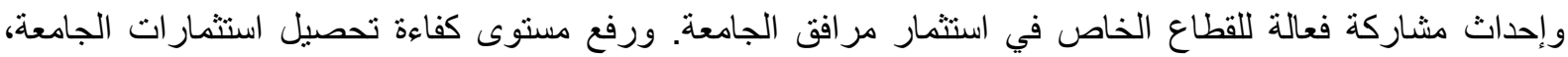
وتحسين مستوى الأداء للمشاريع الاستثمارية، وتسويق الأبحاث ذات الأهية الأهداف التجارية التي يجريها أعضاء الهيئة الأكاديمية و الباحثون و الطلبة.

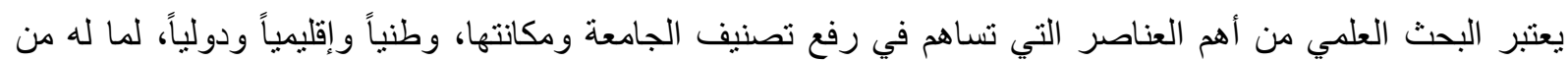

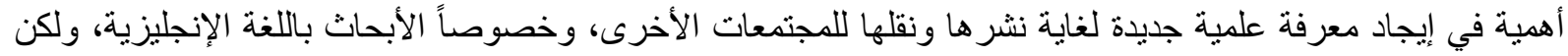

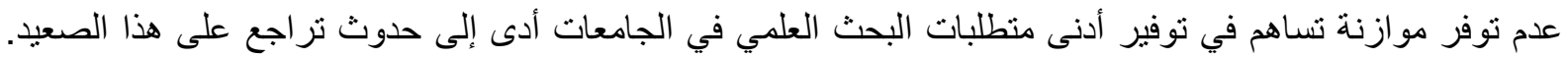

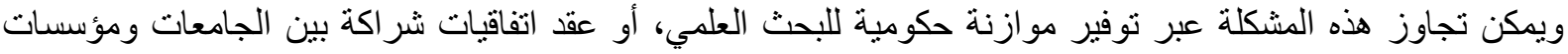

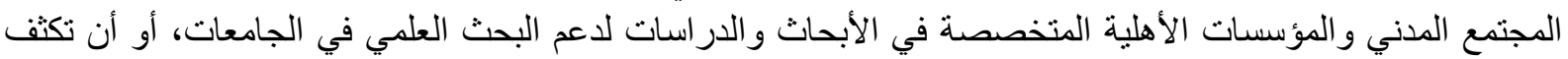

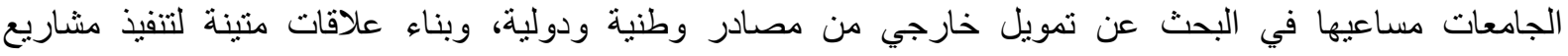

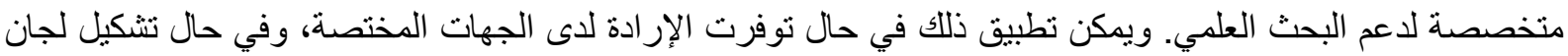

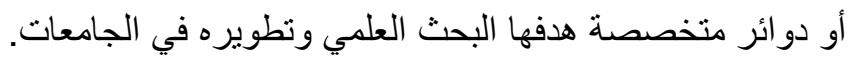
يساهم الخريجون بدور مهم في مجتمعاتهم. وبعد حصولهم على الخبرة العملية، يتطور ويتقام مستوى علاقاتهم وقدرتهم

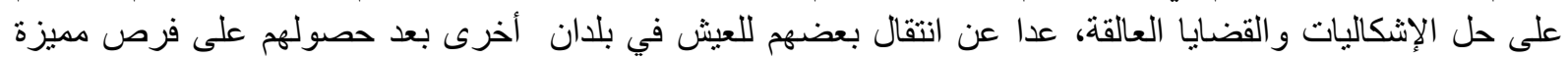
ترفع من مستو اهم المعيثي. ويفترض أن يكون لهؤلاء الخريجين دور كبير في تطوير الجامعات الفلسطينية التي تخرجوا

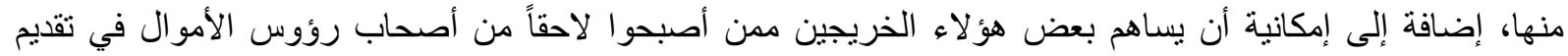

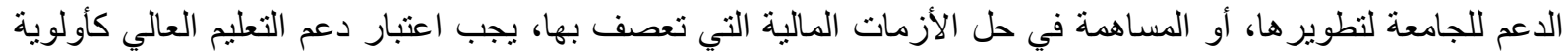

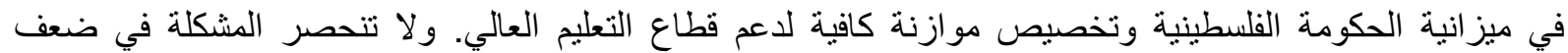

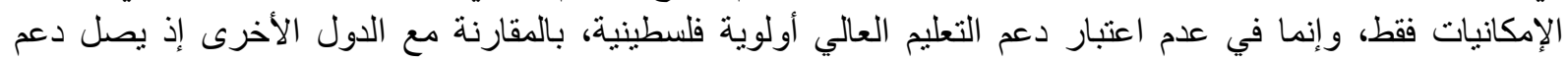

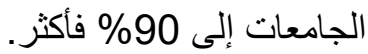

استحداث وتجديد وتطور عمل الوقفيات و المقصود وهي وقف عقات عقار ات أو جزء من أرباح الثركات، أو ودائع مصرفية

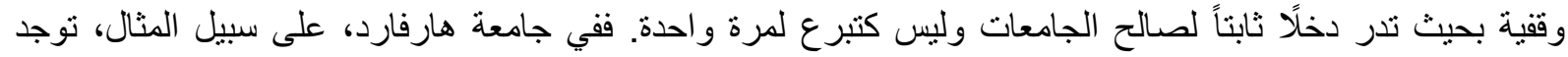

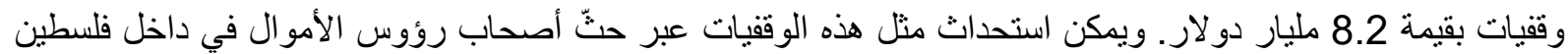

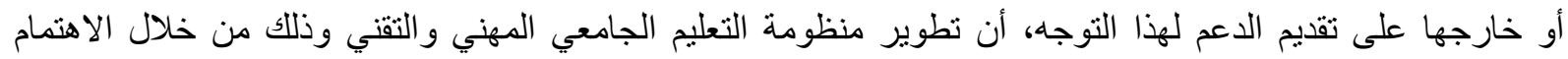
بالتعليم المهني و التقني، و إعطاؤه الأولوية. ففي الوضع الحالي، هنالك 3.5\% من الخريجين تقنيون، بينما تلزم الحاجة ألا

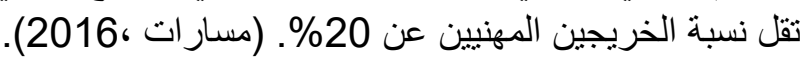




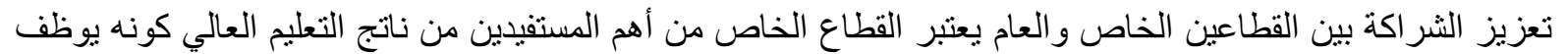

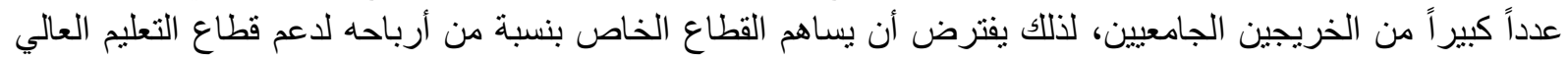

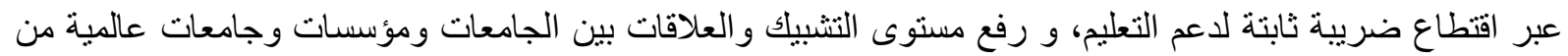

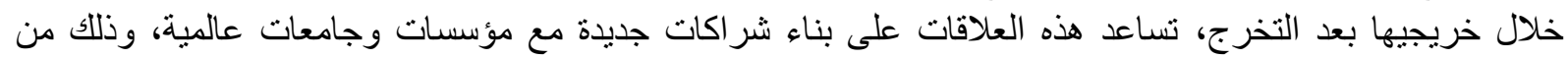

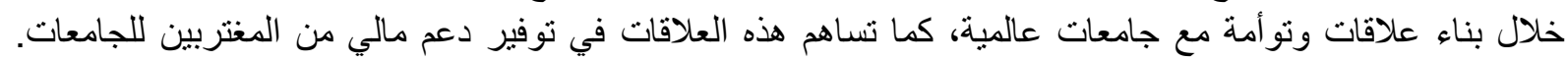

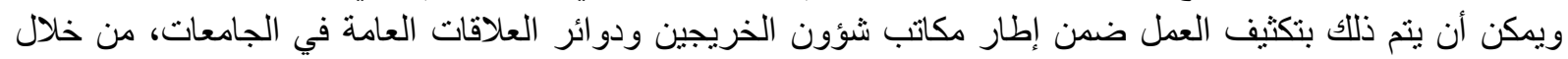
تحديث بيانات الخريجين القدامى، والمتابعة مع الخريجين الجدد باستمر ار للحصول الحئن على على بياناتهم الجديدة.

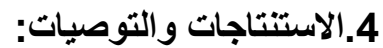

1.4

ان إنشاء مشاريع وحدات استثمار او مر اكز تطوير اعمال على شكل مشاريع إنتاجية يمكن أن تقدم بعض الحلول الممكنة

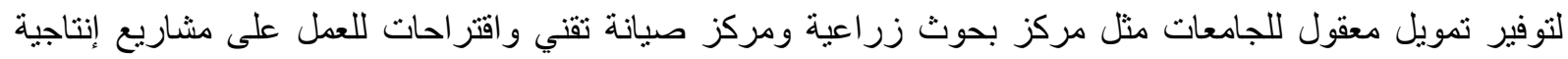

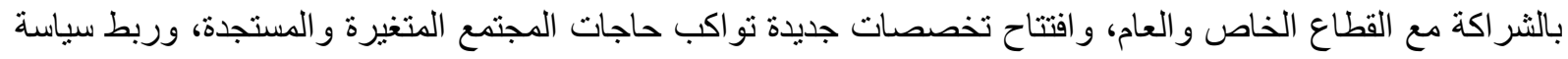

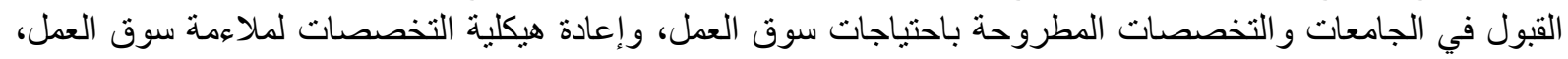

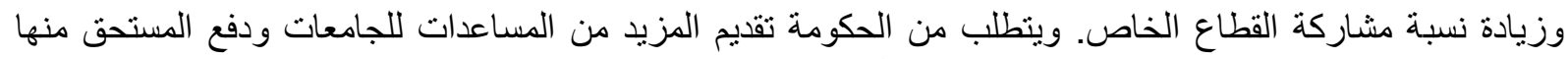

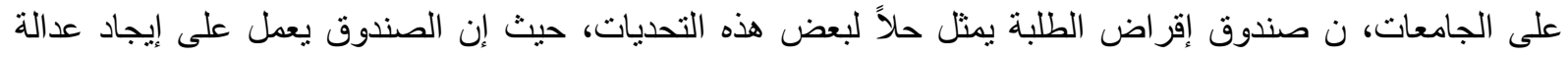

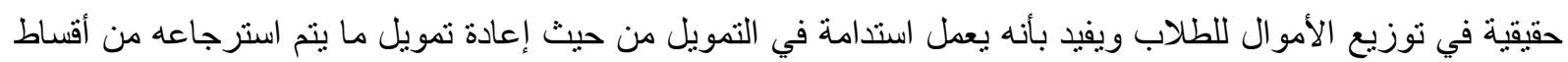

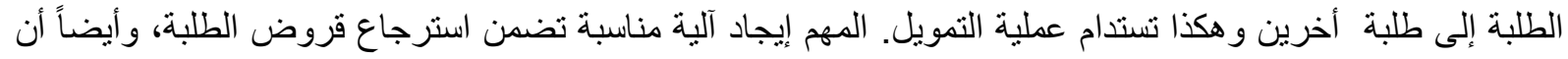

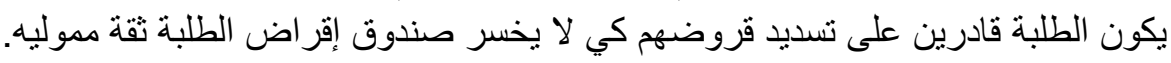

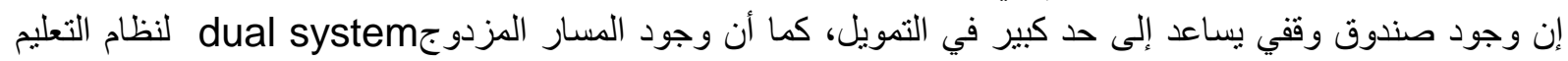

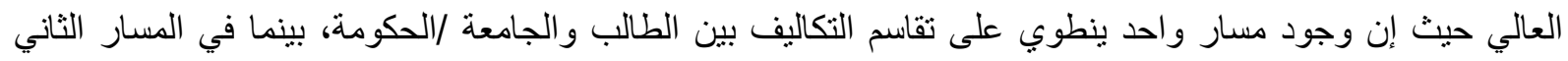

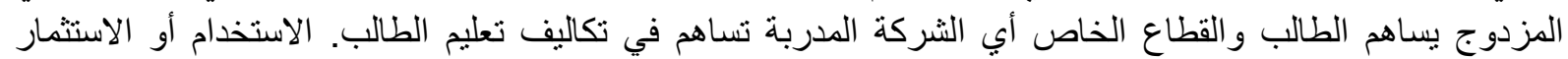

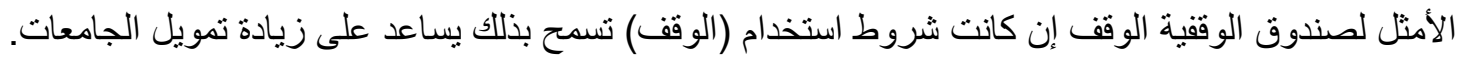

2.4

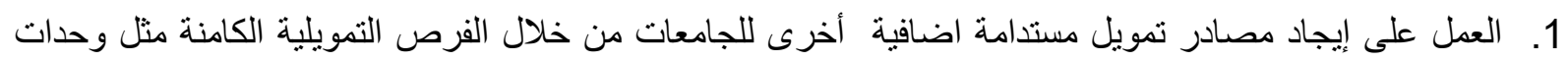

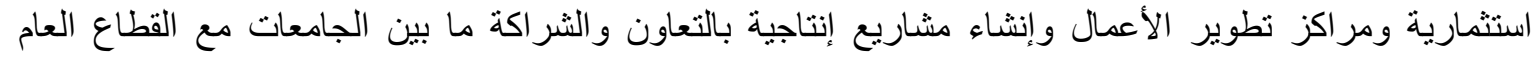

و القطاع الخاص.

2. دم دعم البحث العلمي وتشجيعه و العمل على تسويق البحوث.

3. دعم صندوق إقر اض الطلبة و إيجاد اليات مناسبة لضمان الضمان استمر اريته.

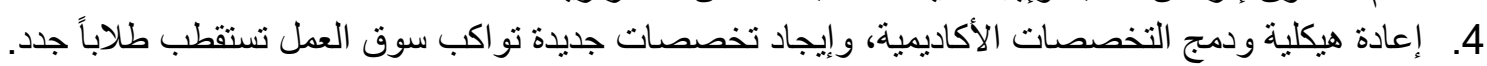

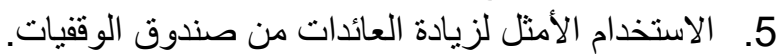

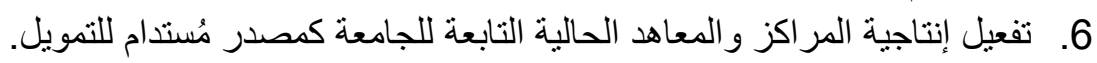
8.

8. تحديد بر امج خاصة في موازنة الحكومة الفلسطينية لدعم تمويل الجامعات والالتز ام بدفع هذه المستحقات المالية.

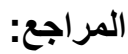

الأمم المتحدة. (2020). تقرير أهداف التنمية المستدامة لعام 2020.

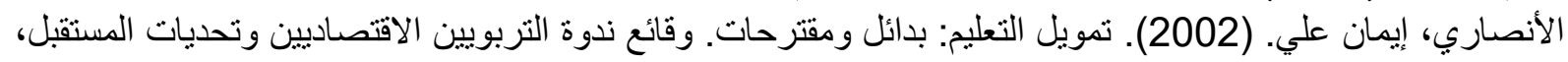

مكتب التربية العربي لدول الخليج.

بطاح، أحمد. الطعاني، حسن. (2016). الإدارة التربوية: رؤية معاصرة. الطبعة الأولى: دار الفكر ناثرون وموزعون، عمان: الأردن. 


\section{OPPORTUNITIES}

بكدار.(2008). المجلس الاقتصادي الفلسطيني للتنمية و الاعمار (بكدار)، نطوير وإصلاح التعليم العالي في فلسطين" الاشكالات والآثار المستقبلية"، فلسطين الإين

بلتاجي، مروة محمد شبل. (2015). تمويل التعليم العالي في مصر: المشاكل والبدائل المقترحة. مجلة كلية الاقتصاد

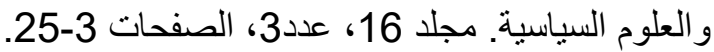

الحملة العربية للتعليم.( 2021). ورقة موقف حملة " إلغاء الديون لصالح مستقبل التعليم". فلسطين. https://www.arabcampaignforeducation.org/page-1521-ar.html

خربوشي، حسني علي (2005) استشر اف تمويل التعليم الجامعي في الأردن: المشاكل والحلول. جامعة الدول العربية ـ المنظمة العربية للتنمية الإدارية، مصر.

الدقي، نور الدين. (2015). تمويل التعليم العام في الوطن العربي، الوثيقة الرئيسة للمؤتمر الخامس عشر للوزراء

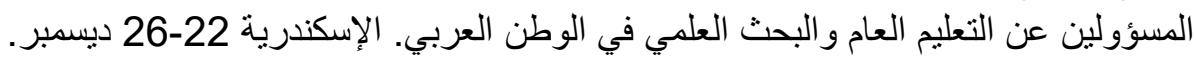

الركبان، أحمد بن غرم الله، الدوسري، راثد ظافر. (2019). ناء سياسة تمويلية للجامعات الأهلية بالمملكة العربية

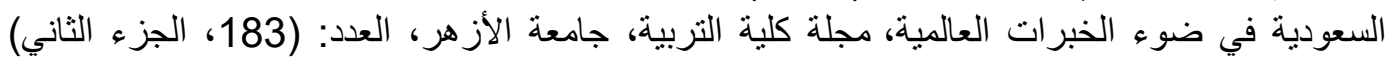

$$
\text { يوليو لسنة 2019م. }
$$

صالح، إبراهيم محمد. (2017). مصادر تمويل التعليم الجامعي في الجمهورية اليمنية. مجلة كلية التربية في العلوم

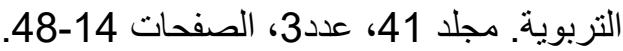

ط.د. ييو كريم. (2019). قياس متغيرات تمويل التعليم بالجزائر. جامعة وهران: الجزائر. مجلة البشائر الاقتصادية، المجلد 5، عدد 2019) (2019).

عبد الجليل، دسوفي. (2019). تمويل التعليم العالي في مصر والإنفاق عليه: بدائل مقترحة لاستر اتيجيات كفاءة وسياسة التمويل. الجمعية المصرية للتربية، المؤتمر العلمي السنوي. التصائ القاهرة.

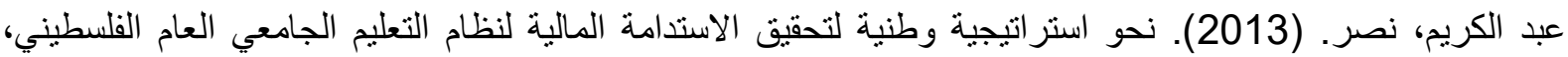

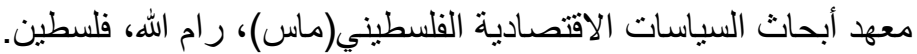

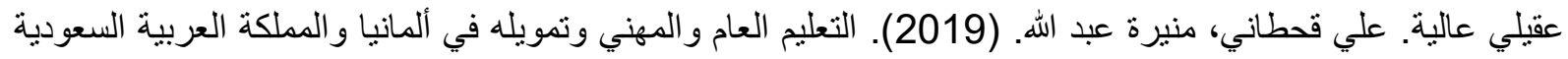
(دراسة مقارنة)، المجلة العربية للعلوم ونشر الأبحاث، مجلة العلوم التربوية و النفسية، المجلد الثالث، العدد

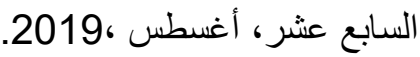

الغافري، راثد. الغافري، سالم. (2005). الاستثمار في التعليم العالي وأهيته في إعداد القوى البشرية المدربة. مؤتمر

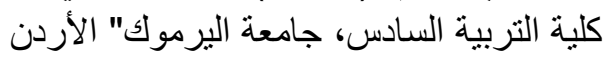

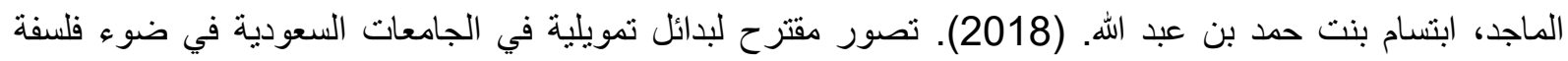

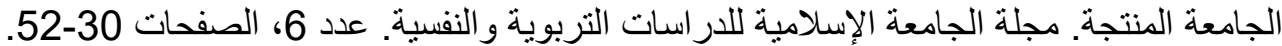

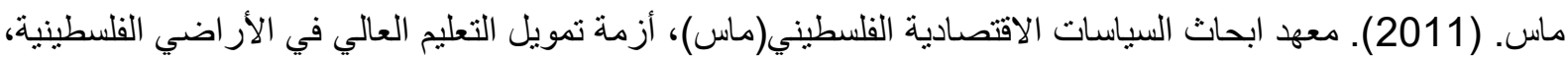

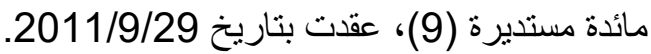

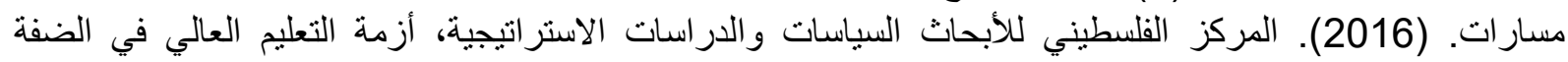
الغربية وقطاع غزة، دراسة منشورة على موقع المركز الالكتروني. .https://www.masarat.ps/article/1810/

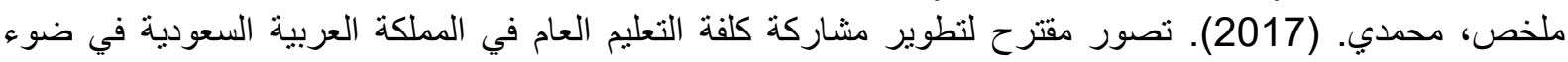

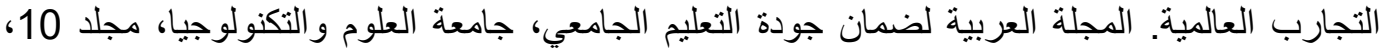

عدد27

المؤتمر الخامس عشر للوزراء المسؤولين عن التعليم العالي والبحث العلمي في الوطن العربي. (2015). تمويل التعليم

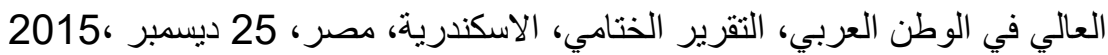

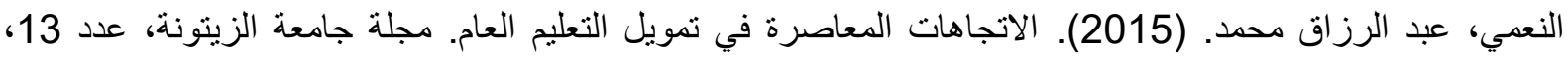

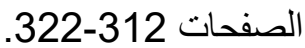

\section{References}

Marginson, Simon. (2018). Global trends in higher education financing: The United Kingdom. International Journal of Educational Development (58),2018. 
Steer, Liesbet and Smith, Katie. (2015). Financing education Opportunities for global action,

Center for Universal Education at the Brookings Institution, NW, Washington ,USA. https://www.brookings.edu/center/center-for-universal-education/ 